\title{
Why the Medical Malpractice Crisis Persists Even When Malpractice Insurance Premiums Fall
}

\author{
Marc A. Rodwin \\ Justin Silverman \\ David Merfeld
}

Follow this and additional works at: https://scholarlycommons.law.case.edu/healthmatrix

\section{Part of the Health Law and Policy Commons}

\section{Recommended Citation}

Marc A. Rodwin, Justin Silverman, and David Merfeld, Why the Medical Malpractice Crisis Persists Even When Malpractice Insurance Premiums Fall, 25 Health Matrix 163 (2015)

Available at: https://scholarlycommons.law.case.edu/healthmatrix/vol25/iss1/9 


\title{
Why the Medical Malpractice Crisis Persists Even When Malpractice Insurance Premiums FALL
}

\author{
Marc A. Rodwin, \\ Justin Silverman, \&6 David Merfeld
}

Contents

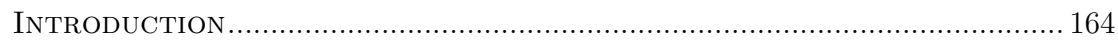

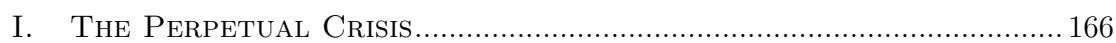

II. Making Sense of Changes in Malpractice Premiums .................. 172

III. The AMA Regional And National Surveys .................................. 176

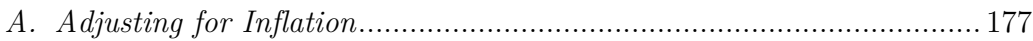

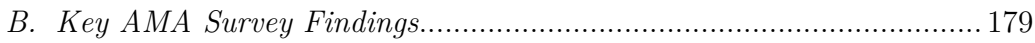

C. A Crisis Within Selected Practice Specialties? ................................ 185

D. A Crisis Among Physicians Paying Higher Than Mean Premiums? .. 187

E. A Crisis Within Specific Regions? .............................................. 188

F. Can AMA Data Be Interpreted to Suggest a Crisis Exists?................ 191

IV. Do Some States Have a Premium Crisis? ....................................... 198

A. Massachusetts as a Test Case ............................................................ 200

B. The Massachusetts Study Data ...................................................... 201

C. How Insurers Set Premiums............................................................... 202

D. Grouping Physicians into Five Practice Tiers ................................... 203

E. 30-Year Manual Rate Trends for the Five Practice Tiers ................. 204

F. Distribution of Physicians by Dollar Amount of Insurance Manual Rates 1990 to 2005 ...................................................................... 206

G. Adjusting Mean Manual Rates for the Number of Physicians in Each Rate Group ..................................................................... 208

H. Relation of Reported Premiums to Premiums of Other Policies......... 209

I. How Manual Rate Discounts and Surcharges Affect the Premiums Physicians Pay.................................................................... 210

J. Obstetrics and Other Tier 1 Practice Specialties ................................ 212

K. An Unrecognized Factor Leading to Selective Increases in

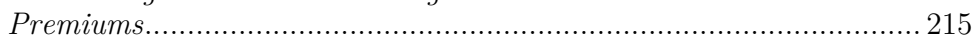

L. Changes in Policies Purchased................................................... 217

Marc A. Rodwin is a Professor of Law at Suffolk University Law School; Justin Silverman is an attorney at law in the law office of Justin Silverman, Esq.; David Merfeld is a CPA in private practice and a graduate of Suffolk University Law School. Thanks to Luke Shiundu Wanami and Soraya Sabri for their research assistance and thanks also to Tasha Levenson for her revisions and to Trish McLaughlin for her help in preparing the figures. 
M. Comparison of ProMutual Group Premiums to Premiums of Other Insurers.....

N. What Causes Premiums to Rise or Fall?

V. Why the Crisis Persists

A. Physicians Mistakenly Perceive a Crisis

B. Key Actors Have an Interest in Maintaining the Perception of a Crisis

\section{INTRODUCTION}

Speaking to a U.S. Congressional committee in February 2003, American Medical Association (AMA) president-elect Donald Palmisano described a medical liability "crisis" bearing down on physicians. ${ }^{1}$ Medical malpractice insurance premiums are at "unprecedented levels," he said. ${ }^{2}$ Health centers are closing. ${ }^{3}$ Patients are leaving their state to find care. ${ }^{4}$ Emergency departments are losing staff. ${ }^{5}$ Physicians can no longer afford - or even find-liability insurance necessary to practice. ${ }^{6}$ This is occurring, Palmisano said, because "premiums are spiking across all specialties."

The concern over premium prices continues today, with physicians and politicians alike crying foul over what they perceive to be the escalating and debilitating cost of medical malpractice insurance. This perception has helped generate the impetus for dozens of federal and state legislative proposals aiming to curb what many

1. Assessing the Need to Enact Medical Liability Reform Before the Subcomm. on Health of the H. Comm. on Energy and Commerce, 108th Cong. 68 (2003) [hereinafter Hearings] (statement of Donald J. Palmisano, President-elect, American Medical Association). The AMA has been one of the main groups that advocates for legal changes to make it more difficult for injured patients to recover compensation from physicians in lawsuits and to cap the amount of their compensation if courts find physicians liable. In advocating for such changes, the AMA has asserted the following position in public statements and testimony before Congress: (1) the cost of malpractice insurance has risen steadily and unabatedly; (2) that high premiums threaten the economic viability of medical practice and thereby precipitate a crisis; and (3) that malpractice premiums cause physicians to either stop practicing medicine or relocate to states solely in order to obtain malpractice insurance at lower cost.

2. $\quad$ Id. at 70 .

3. $I d$.

4. $\quad I d$. at 69 .

5. Id. at 70 .

6. $I d$.

7. Id. at 71 . 
sense are out-of-control costs. In the 108th and 109th U.S. Congresses alone, twenty-six bills were introduced to address this "rise in malpractice premiums." 8 These bills sought to change the rules of tort liability for medicine, to provide tax credits for premiums as relief, and to establish a commission to investigate the reasons that caused the rise in premiums, among other actions. ${ }^{9}$ Palmisano and the AMA joined with other groups to advocate for such legislation. In fact, the AMA website even includes a map indicating states in crisis, testimonials, and articles. ${ }^{10}$

Many of these bills, however, use caps to limit patient recovery and physician liability. ${ }^{11}$ Rather than focusing on the prevalence of malpractice itself, much of this legislation challenges a patient's right to recover and leaves many of these patients vulnerable, especially those without income, such as the retired, homemakers, and children. Even if malpractice premiums are indeed high, other less damaging and more effective options exist with which to counteract high premiums. They include reducing the incidence of medical injury or finding other ways to pay for insurance or compensate injured patients.

"Malpractice lawsuits are the compensation tool that we have," wrote Tom Baker in his 2005 book, The Medical Malpractice Myth. ${ }^{12}$

8. In the 108th Congress, the bills were H.R. 1116, 108th Cong. (2003); H.R. 1124, 108th Cong. (2003); H.R. 1158, 108th Cong. (2003); H.R. 321, 108th Cong. (2003); S. 1374, 108th Cong. (2003); H.R. 1178, 108th Cong. (2003); H.R. 4124, 108th Cong. (2004); H.R. 446, 108th Cong. (2003); H.R. 447, 108th Cong. (2003); H.R. 485, 108th Cong. (2003); H.R. 1044, 108th Cong. (2003); H.R. 1249, 108th Cong. (2003); and S. 352, 108th Cong. (2003); in the 109th Congress, they were: H.R. 2657, 109th Cong. (2005); H.R. 2400, 109th Cong. (2005); H.R. 2291, 109th Cong. (2005); H.R. 2399, 109th Cong. (2005); S. 354, 109th Cong. (2005); S. 367, 109th Cong. (2005); S. 366, 109th Cong. (2005); H.R. 2731, 109th Cong. (2005), and S.1012, 109th Cong. (2005). Since then bills have been introduced to limit damage awards rather than to cap premiums. See H.R. 5480, 110th Cong. (2008); Patient Protection and Affordable Care Act, H.R. 3590, 111th Cong. (2009); H.R. 3459, 111th Cong. (2009); S. 2662, 111th Cong. (2009); S. 1734, 111th Cong. (2009); S. 1099, 112th Cong. (2011); and H.R. 4106, 113th Cong. (2014).

9. See note 8 supra and accompanying text.

10. Am. Med. Assoc., America's Medical Liability Crisis Map (on file with the author).

11. See, e.g., David A. Hyman et al., Do Defendants Pay What Juries Award? Post-Verdict Haircuts in Texas Medical Malpractice Cases, 1988-2003, 4 J. EMPIRICAL LEgal StUd. 3, 38 (2007).

12. Tom Baker, The Medical Malpractice Myth 111 (2005); for another leading synthesis on medical malpractice, see FrANK A. SLOAN \& Lindsey M. Chepke, Medical Malpractice (2008); for a collection of interesting contemporary analyses, see generally William M. SAGE \& 
"It would be a terrible mistake to make that tool harder to use without giving people something better in its place." ${ }^{13}$ Not only would this legislation make lawsuits more difficult for plaintiffs, but the bills do not address the real source of the problems that they intend to solve. Premiums are not rising as claimed and even if they were, other factors are contributing to the plight of physicians. As Baker aptly titled his book, the medical malpractice "crisis" is more myth than fact. ${ }^{14}$

Part I of this Article examines how this myth began and the proposed legislative remedies that it spawned. Part II shows that junk data has been used to support legislation while introducing more reliable data bearing on these issues. Part III describes other factors that are rarely mentioned, but that have important effects on the cost of medical practice and physician income. If doctors are truly closing up shop, then malpractice insurance premiums are not the cause. Part IV then examines one AMA-declared "crisis state" to see if there are indeed crises in some selected states, even if there is no crisis nationally. As this Part shows, there are none; rather, the study of individual states reveals that premiums rise and fall cyclically, that recent premium increases reflect these cycles, and that rates will probably fall as they have in the past whenever there has been an increase in rates. This Article concludes by offering insight into why physicians continue to perceive a crisis despite the data presented and what the future may hold for reform.

\section{The Perpetual Crisis}

The conventional wisdom today suggests that malpractice premiums are crushing practices and that the appropriate response is to restrict compensation for injured patients. For example, in 2006, U.S. Senate leaders introduced the Medical Care Access Protection Act and the Healthy Babies Access to Care Act in order to reduce the cost of liability insurance. ${ }^{15}$ The sponsors of the measure intended to drive down the cost of premiums by capping malpractice compensation under the assumption that insurance rates are increasing. ${ }^{16}$ To do so, the bills prohibited punitive damage awards

Rogan Kersh, Medical Malpractice and the U.S. Health Care SYSTEM (2006).

13. BAKER, supra note 12 , at 111 .

14. Id.

15. Medical Care Access Protection Act of 2006, S. 22, 109th Cong. $\S 8$ (2006); Healthy Mothers and Healthy Babies Access to Care Act, S. 244, $110^{\text {th }}$ Cong. $\S 8$ (2007).

16. S. 22; S. 244. 
that in excess of two and a half times the economic loss or $\$ 250,000$, whichever is greater. ${ }^{17}$

To justify such bills, legislators and physicians across the country depict a devastating scenario: "For years, the price of medical malpractice insurance has soared to record breaking levels," said Representative Juan Hinojosa (Texas) in May 2005. ${ }^{18}$ "Medical school students are no longer interested in specialties and sub-specialties because of the yearly price they must pay to simply practice their craft." ${ }^{19}$ In Illinois, according to the AMA, "it is a simple fact that the state's out of control legal system has driven insurance premiums skyhigh and forced high-risk specialists, including neurosurgeons and obstetrician-gynecologists, to restrict services, retire early and leave the state. . . . Anyone driving through the state could lose their life because of this crisis." ${ }^{20}$ New York State Senator John Flanagan, who sponsored legislation in 2008 that would decrease the amount of liability insurance needed by physicians to practice, stated that "Malpractice insurance rates are pushing doctors out of our state." 21

In January 2003, U.S. Representative Peter DeFazio proposed a federal commission to examine the causes of "skyrocketing malpractice insurance premiums."22 DeFazio's home state of Oregon is one of twenty in a medical liability crisis, according to the AMA. ${ }^{23}$ Such states, said the AMA, reflect a national trend in which patients are losing access to care due to physicians retiring early, relocating to other states, and restricting services, such as no longer delivering babies or performing high-risk surgeries. ${ }^{24}$

As it is often argued, all this is occurring because malpractice insurance premiums are spiking, as they did in the 1970s. During that time, a flood of state legislation attempted to stem the costs of insurance through reforms of malpractice liability law. That

17. S. $22 ;$ S. 244.

18. Rep. Hinojosa Gives Doctors a Break, U.S. FED. News, May 18, 2005, available at 2005 WLNR 8130861.

19. Id.

20. Press Release, Am. Med. Ass'n ., AMA Applauds President's Call for Medical Liability Reform (2005), http://www.philamedsoc.org/community/Resources/phl\%20med\%2002_ 05.pdf.

21. Senate Passes Medical Malpractice Insurance Legislation, U.S. STATE NEWs, Apr. 15, 2008, available at 2008 WLNR 9871447.

22. Emergency Malpractice Liability Insurance Commission Act, H.R. 446, 108th Cong. $\S 3$ (2003).

23. Press Release, Am. Med. Ass'n., AMA: Together We Can Fix Oregon's Medical Liability Crisis (2005) (on file with the author).

24. $I d$. 
legislation is now considered largely ineffective, but at the time, it quelled most concerns about increasing rates. ${ }^{25}$

Compare the claims of forty years ago to those made in recent years. The similarities are striking. A group of Long Island physicians threatened "to treat only emergency patients" unless they received "reasonably priced" malpractice coverage. ${ }^{26}$ Anesthesiologists in California and Ohio declared the same. ${ }^{27}$ New York physicians claimed that high premiums were either forcing them to leave the state or retire early. ${ }^{28}$ Doctors were not only moving from "heavily populated cities such as New York and Los Angeles to rural areas," but also leaving the country to practice abroad. ${ }^{29}$ They were fleeing "to other states where there are fewer malpractice suits, smaller judgments and thus more reasonable insurance rates." 30

The same panic existed then as it does now. But despite the ineffective legislation, the increase in rates abated as they are likely to again. Some physicians actually acknowledge this, noting that premiums have not increased without pause. ${ }^{31}$ They point to three periods of particularly high premiums - 1970 to 1975 ; 1980 to 1990; and 1996 to the present-yet many physicians now claim that premiums are now at a breaking point. ${ }^{32}$ Some data, as will later be explained, actually suggest that once adjusted for inflation, medical malpractice premiums actually decreased between 1986 and 2000. ${ }^{33}$

When Palmisano addressed the U.S. House of Representatives in 2003, he did so in support of the Help Efficient Accessible Low-Cost Timely Healthcare (HEALTH) Act. ${ }^{34}$ This bill, like many before and after it, suggested reforms to make malpractice insurance more affordable for physicians. "Our healthcare system is facing a crisis," Palmisano said, "when community health centers have to reduce their

25. Frank A. Sloan, Responses to the Malpractice Insurance "Crisis" of the 1970s: An Empirical Assessment, 9 J. HeATH POL. POL'Y \& L. 629, 629 (1985).

26. Malpractice: The State Steps In, Time, May 5, 1975, at 82.

27. Id.

28. Malpractice Mess, Time, June 9, 1975, at 18.

29. Malpractice: MDs Revolt, NewsweEK, June 9, 1975, at 58.

30. Id.

31. Sloan, supra note 25.

32. Id.

33. $I d$.

34. Hearings, supra note 1 , at 76 .

35. H.R. 5, 108th Cong. (2003). 
services or close their doors because of liability insurance concerns." ${ }^{36}$ Yet, those concerns are not well founded. So why do they exist?

Those who in recent years claimed that there is an ongoing crisis base that claim on anecdotes, unsupported assertions, and flawed data. ${ }^{37}$ Palmisano and others flouting evidence of rising premium costs, cite the Medical Liability Monitor Reporter (MLMR). ${ }^{38}$ For the last decade, nearly all data in scholarly articles and reports by government agencies were based on data from the MLMR, which sells data on malpractice insurance pricing trends. ${ }^{39}$ It obtains premium data from various insurance company rate sheets and, based on these rate sheets, reports average premium increases and decreases and average rates. ${ }^{40}$ It generates numbers that sound precise and make for compelling sources in newspaper or reports.

For example, when the Associated Press detailed Florida's "particularly difficult medical malpractice climate" in 2007, it cited MLMR data. ${ }^{41}$ The Pittsburgh Post-Gazette did as well when reporting about, "malpractice fees driving away young doctors" in 2005. ${ }^{42}$ That same year, the Rochester Democrat and Chronicle compared the plight of its physicians with those in New Jersey and Virginia, many of whom "stopped seeing patients to protest too-costly medical malpractice insurance." ${ }^{43}$ It too cited MLMR data, ${ }^{44}$ as do many other newspaper articles and trade publications. ${ }^{45}$ Many

36. Hearings, supra note 1 , at 2 .

37. Marc A. Rodwin, et al., Malpractice Premiums and Physicians' Income: Perceptions of a Crisis Conflict with Empirical Evidence, 25 HEALTH AFF. 750, 757 (2006).

38. Id. at 750 .

39. Medical Liability Monitor Reporter 27 (Aug. 2002) (on file with the author); see also Medical Liability Monitor REPorTer 28 (Oct. 2003) (on file with the author).

40. Medical Liability Monitor, http://www.medicalliabilitymonitor.com (last visited Feb. 26, 2015).

41. LMS and Best Practices Medical Partners Enter Agreement for CALM Shoulder Screen Risk Management Tool, PR NEWSWIRE (Aug. 21, 2007), http://www.prnewswire.com/news-releases/lms-and-best-practicesmedical-partners-enter-agreement-for-calm-shoulder-screen-riskmanagement-tool-58318962.html.

42. See generally, Jacqueline Shoyeb, Study: Pa. Malpractice Fees Driving Away Young Doctors, PittsBurgh Post-GazetTe, July 18, 2005, at $\mathrm{A} 1$, available at 2005 WLNR 11251412.

43. Joy Davia, Malpractice Insurance Soars, RocheSTER DEMOCRAT \& Chronicle, Feb. 25, 2003, available at 2003 WLNR 17961223.

44. Id. 
scholarly articles on medical malpractice and government reports also cite MLMR data. ${ }^{46}$

Even the AMA, despite having its own contradicting evidence, cites MLMR studies and uses them in support of its proposed restructuring of medical malpractice law. ${ }^{47}$ Indeed, the AMA has used data from the MLMR to support its position on medical liability insurance premiums. As recently as 2008, for example, the AMA proclaimed that "tort reforms work," touting a then-recent analysis of medical liability and 2007 MLMR data. "This tells the story again: Tort reform works, and this just reaffirms it for the umpteenth time," said AMA Immediate Past President William G. Plested, III, in American Medical News, an AMA publication. ${ }^{49}$ "In this day and age of evidence-based medicine, we ought to have evidence-based tort reform. ${ }^{.50}$

Compelled by concerns of physicians across the country and Congressional requests for a report, the U.S. General Accounting Office (GAO) investigated rising malpractice premium rates and

45. See generally, Brandon Stahl, High-risk Health Providers Stay in Business Thanks to State Insurance, STAR TRIBUne, May 5, 2013, http://www.startribune.com/local/206125891.html; Darshak Sanghavi, Medical Malpractice: Why is it so Hard for Doctors to Apologize?, Bost. GLOBE, Jan. 2013, http://www.bostonglobe.com/magazine/2013/01/27/medicalmalpractice-why-hard-for-doctorsapologize/c65KIUZraXekMZ8SHIMsQM/story.html; Christopher Flavelle, Op-Ed, Pay Doctors Less, Pittsburgh Post-Gazette, Dec. 14, 2012, http://www.post-gazette.com/opinion/OpEd/2012/12/14/Pay-doctors-less/stories/201212140254; Katharine Q. Seelye \& Andrew Keh, Parent's Right, or Professional's Privacy?, N.Y. Times, Feb. 3, 2011, at A14.

46. See, e.g., Leonard J. Nelson et al., Medical Liability and Health Care Reform, 21 Health Matrix 443, 469 (2011); Aaron E. Carroll et al., The Impact of Defense Expenses in Medical Malpractice Claims, 40 J.L. MeD. \& EThics 134, 135 (2012); Jessica Wolpaw Reyes \& Rene Reyes, The Effects of Malpractice Liability on Obstetrics and Gynecology: Taking the Measure of a Crisis, 47 NEw EnG. L. REv. 315, 321 (2012).

47. See, e.g., Amy Sorrel, AMA Analysis Reaffirms: Tort Reforms Work, AM. MED. NEws (Mar. 3, 2008), http://www.amaassn.org/amednews/2008/03/03/prsa0303.htm.

48. $I d$.

49. See 2002 Rate Survey Finds Malpractice Premiums Are Soaring, MED. LiABILITY MONITOR, Oct. 2002, at I-IV (on file with the author); $A M A$ Analysis Reaffirms: Tort Reform Works, AM. MED. News (Mar. 3, 2008), available at http://www.amaassn.org/amednews/2008/03/03/prsa0303.htm.

50. AM. MED. NEWs, supra note 49. 
possible causes in $2003 .^{51}$ Rather than obtain its own data, or review multiple sources of existing data, however, the GAO relied on the MLMR data and presumed that it showed a crisis. ${ }^{52}$ The GAO reported that due to "large increases in medical malpractice insurance premium rates... physicians will no longer be able to afford malpractice insurance and will be forced to curtail or discontinue providing certain services." ${ }^{153}$

But the MLMR data is not reliable. Industry insiders do not put much stock in its data, says Stephen Langlois director of underwriting-actuarial services at the ProMutual Group. ${ }^{54}$ And for good reason. MLMR data averages the rates paid by physicians as if they all purchase the same number of policies from the same insurer. This skews the data. For example, if MLMR surveys three insurers in one market and averages their rates, each rate will count for one-third of the average. But one firm might insure more than half of the physicians surveyed, a second, only 30 percent, and the third only 10 percent. The MLMR average does not reflect those differences.

Another problem is that the MLMR does not distinguish between rates for different practice specialties or for different kinds of insurance policies. That might be acceptable if all physicians paid more or less the same premium. But in fact, insurance rates vary based on practice specialty, and the kind of policy coverage that physicians purchase. As we will see later, most insurers distinguish between about seven types of policies based on their duration. Insurance rates also vary depending on the level of liability protection that physicians purchase. Averages across all policies do not reflect those differences. In addition, the MLMR reports on insurance rates that firms file with state regulators, not the actual amount that physicians pay for insurance. These rates act more like a sticker price for a car rather than the negotiated and paid amount.

States regulate insurance rates so insurers cannot raise those rates without state authorization. As a result, insurers seek approval for high rates to protect their ability to charge that much, but in practice they discount those policies based on market competition. High rates allow insurers the flexibility to vary charges based on changing conditions without having to wait until the next period for rate

51. U.S. Gov't ACCOUntability Office, GAO-03-702, MedicAl Malpractice Insurance: Multiple Factors Have Contributed to InCREASEd PREMiUm RATEs 1 (2003) [hereinafter GAO REPORT].

52. Id. at 9 .

53. Id.

54. Interview with Stephen Langlois, Director of Underwriting-Actuarial Services, ProMutual Group (2005). 
increases or without having to take the risk that regulators will not approve future rate increases.

Insurers also have a competitive advantage by not revealing to their competitors the actual amounts that they charge customers. Without that information, competitors do not know how much they can raise prices without the risk of losing customers. They are also unaware of the dollar amount by which they need to reduce their prices in order to attract customers from competing insurers.

Differences between regulated rates and discounted premiums also make it more difficult for a firm to know the reason that a competitor offers a physician a lower premium than it otherwise would. The firm's competitor might have offered a lower premium because it believed the physician had a lower risk of loss than the firm's own evaluation or the competitor might simply be willing to assume the physician's risk of loss for a lower fee than the firm would. In fact, people working in the medical malpractice insurance industry report that since 1990, most of them use manual rates as a baseline and vary the amount they charge individual physicians. ${ }^{55}$

Yet another concern with the MLMR and most similar publications is that they usually report the percentage change in rates, not the actual dollar amount. That can make changes appear much greater than they actually are when premiums are low. For example, if insurance rates are $\$ 10,000$, raising premiums by $\$ 2,000$ to $\$ 12,000$ would be a 20 percent increase. However, a $\$ 2,000$ increase in a physician's premiums does not have a major impact on her practice viability if the physician's gross practice revenue is $\$ 500,000$ and her total practice expenses are about half of revenue, or $\$ 250,000$. If other practice expenses do not change, the physician's net income would fall from $\$ 250,000$ to $\$ 248,000$. Taking all this into account, it is not surprising that in recent years some scholars have criticized the reliability of the MLMR data for tracking premium costs. ${ }^{56}$

\section{Making Sense of Changes in Malpractice Premiums}

To understand the effect of changes in malpractice insurance premiums on a physician's practice requires a comparison of those

55. $I d$.

56. See, e.g., Kathryn Zeiler et al, Physicians' Insurance Limits And Malpractice Payments: Evidence From Texas Closed Claims, 1990-2003, 36 J. LEgal Stud. s9, s37 (2007). ("[E]mpirical studies that fail to address policy size may generate findings that are suspect. For example, the Medical Liability Monitor (MLM), a widely used source of data, provides pricing information for $\$ 1$ million primary policies. If many or most doctors carry policies with different limits, MLM-based studies may mischaracterize trends in insurance pricing."). 
premiums to total practice expenses and revenue. First, premiums paid should be compared to other practice expenses. These expenses include office rent or mortgage payments, medical equipment and supplies, non-physicians' salaries, office utilities, office supplies, and other overhead expenses. That information is necessary to show the relation between premiums, other practice expenses, and total practice expenses.

Second, total practice expenses should be compared to gross practice revenue. This information shows the relationship between practice expenses and net practice income. Net practice income equals gross practice revenue minus total practice expenses before payment of taxes. Together, this information shows the relative importance of premiums to other practice expenses.

Even if premiums are escalating, they may not cause the financial woes that are so often claimed. By considering total practice expenses, it appears that insurance rates are not the lone culprit - if one at allfor raising costs of medical practice. A 2011 report by the Medical Group Management Association, for example, found that general operating expenses rose nearly 53 percent in the last decade. ${ }^{57}$ Partly responsible for that increase were support staff expenditures (4.8 percent) and supply costs (7.4 percent)..$^{58}$

It is also important to distinguish between short term premium increases or declines and long term trends. Claims such as the ones made by proponents of tort reform in the beginning of this article give the impression that rates continue to increase every year and never decrease. This is not the case. Studies show that they rise and fall in predictable cycles, just as premiums do for other insurance. ${ }^{59}$

"Insurance markets cycle through periods of low prices and ample supply (called soft markets) and periods of high prices and scarce supply (called hard markets)."60 During soft markets, there are relatively low claim costs and insurers are more able to lower prices and attract more business. ${ }^{61}$ A soft market existed prior to the $1970 \mathrm{~s}$,

57. John Commins, MGMA: Docs Trim Practice Expenses, But Operating Costs Soar, HealthLeaders Media (Sept. 22, 2011), http://www.healthleadersmedia.com/content/LED-271265/MGMADocs-Trim-Practice-Expenses-But-Operating-Costs-Soar\#\%23.

58. Id.

59. Tom Baker, Medical Malpractice and the Insurance Underwriting Cycle, 54 DePaul L. Rev. 393, 409 (2005); see generally Kurt Karl et al., Capital Markets and Insurance Cycles, 4 J. Risk FinANCE 40, 40 (2003).

60. Michelle M. Mello, The Robert Wood Johnson Found, Understanding Medical Malpractice Insurance: A Primer 12 (2006).

61. Id. 
before malpractice claims increased, costs of insuring physicians for liability rose, insurers raised premiums and some insurers dropped out of the market. ${ }^{62}$ When a change in the market like this occurs, however, it typically stabilizes in a few years. ${ }^{63}$ Hard markets ultimately soften again, providing a more competitive insurance market and driving insurance rates back down.

The cycle reflects a forecasting error; that is, the difference between what insurers thought their losses would be over a short period of time and what their losses actually were. ${ }^{64}$ Unlike other insurance markets, the consequences of a forecasting error can be severe because claims are often not filed until two to three years after the alleged malpractice occurs. ${ }^{65}$ Insurer forecasts consider not only losses from existing claims, but potential losses from claims that will be filed in the future. ${ }^{66}$

Baker examined one such cycle that occurred between 1980 and $2002{ }^{67}$ By plotting the difference in what insurers predicted their losses to be and what they actually were, a trend emerges that mirrors the rise and fall of premium rates. ${ }^{68}$

In 1980, medical malpractice insurers experienced losses higher than they anticipated, leading to a drop in profits. ${ }^{69}$ For the next six years, a hard market continued with declining profits causing insurers to raise premiums to compensate for the loss in revenue. ${ }^{70}$ Then the market turned..$^{71}$ In 1986, predicted losses exceeded actual losses so insurers found themselves with more money in their reserves and a greater profit. $^{72}$ Insurance premiums began to decrease in price because insurers could now afford more competitive policies. ${ }^{73}$ This soft market continued until 1996, when actual losses began to exceed

62. Barry R. Furrow et Al., 2 Health law 349 (2d ed., 1995).

63. See Mello, supra note 60 , at 12 .

64. Id.

65. Id.

66. Id.

67. Baker, supra note 59, at 53.

68. Id.

69. Id.

70. $I d$.

71. Id.

72. Id.

73. See id. at 57 . 
predicted losses again and profits suffered. ${ }^{74}$ With profits down, insurance rates again began to rise. ${ }^{75}$

Other factors that affect the underwriting cycle are fluctuations in interest rates and the performance of the stock market. The insurance industry generates income by charging premiums and by investing the money brought in from premiums. These two main sources of revenue-premiums and the investment of premiums - allow the insurance industry to shift dependency between revenue streams. In periods of high interest rates, it is possible for an insurance company to rely more heavily on investment income. This exacerbates the underwriting cycle as the increased investment income derived from high interest rates further enables an insurance company to write policies below fair market value. A report by the U.S. General Accounting Office (GAO) on medical malpractice premiums found that a drop in investment income of 1 percent requires a 4 percent increase in the premium charged to make up for the difference. ${ }^{76}$

The performance of the stock market affects insurance investment earnings as well. Industry experts estimate that 15 percent of insurance company investments are in the stock market. ${ }^{77}$ When the stock market is performing well, as it did during the late 1990s, increased income from stock market investments further enables an insurance company to write policies below fair market value. When investment income drops, this exacerbates an upswing in the underwriting cycle, as rates on premiums must increase, not only to compensate for past policies written below fair market value, but also to make up for the reduced income from poor investment performance. This occurred in the mid-1980s when malpractice premiums increased dramatically after historically high interest rates declined and the insurance market then experienced an upswing in the underwriting cycle. ${ }^{78}$ Insurance companies were forced to increase premiums in order to offset both the reduction in revenue from

74. Id.

75. RODWIN ET AL., supra note 37 , at 755 .

76. GAO REPORT, supra note 51 , at 27 .

77. AM. ACAD. OF ACTUARIES, Subcomm. on Oversight and Investigations Comm. on Energy and Commerce U.S. House of Representatives Hearing on "Pennsylvania Medical Liability Insurance Crisis" (statement of James Hurley, ACAS, MAAA Chairperson), available at http://www.actuary.org/files/medmal_10feb03.4.pdf/medmal_10feb03. 4.pdf.

78. David J. Nye et al., The Causes of the Medical Malpractice Crisis: An Analysis of Claims Data and Insurance Company Finances, 76 GEO. L.J. 1495, 1526 (1988); John Conyers, Jr., The Health Act - A Bad Prescription for Consumers, 27 Seton Hall Legis. J. 191, 193 (2003). 
investment income and to compensate for the low premiums that had been charged in the late 1970 s and early 1980 s. $^{79}$

The cycles that these rates follow directly rebuke the claims of skyrocketing premiums. Ironically, there is data that supports all of this in a study conducted by one of the main parties perpetuating the medical malpractice myth: the American Medical Association.

\section{The AMA National And Regional Surveys}

Despite media reports on malpractice insurance relying on anecdotes or the MLMR, there is a source of comprehensive, detailed, and reliable data on the amounts that physicians paid for malpractice insurance. ${ }^{80}$ Starting in 1970 and continuing annually through 2000, the AMA surveyed self-employed U.S. physicians on many aspects of their medical practice. ${ }^{81}$

Physicians reported malpractice premiums and other expenses as well as gross practice revenue. The AMA data thus reveals net practice income (i.e., gross practice revenue minus total practice expenses) as well as its relation to malpractice premiums. ${ }^{82}$ The AMA surveys also identify expenses and revenue by practice specialty,

79. Conyers, supra note 78, at 193.

80. The surveys were conducted by the AMA Center for Health Services Research (1970-1992), Socio-Economic Monitoring System (1992-1999), and the Patient Center Physician Survey (2000). The AMA published this data in numerous publications, some of which reported data for one year only and others reported data for more than one year. There was often a lag between when the data was collected and when the AMA published reports analyzing the data. Unless otherwise provided, all figures (1-10) in Part III of this article rely on AMA data from one or more of the follow data sources. 1970 data from AM. MED. Ass'N, Profile of Medical Practice (S. G. Vahovich ed., 1973); 1986 data from Am. Med. Ass'n, Physician Marketplace Statistics 1978-1998 (M. L. Gonzalez \& P. Zhang eds., 1999); Am. Med. Ass'n, Physician Marketplace Statistics (M. L. Gonzalez ed., 1988); 1996 data from Am. Med. Ass'N, Physician Socioeconomic Statistics 1997-1998 (M. L. Gonzalez \& P. Zhang eds., 1998); and 2000 data from AM. MED. Ass'n, Physician Socioeconomic Statistics 2000-2002 (J. D. Wassenaar \& S. L. Thran eds., 2003) [hereinafter AMA SuRvEYs].

81. These AMA surveys collected data from self-employed physicians who were engaged in solo or group practice, which in 2000 represented $61.5 \%$ of practicing physicians in the United States.

82. The AMA surveys report a wide variety of data. It consistently reported national mean values for practice expenses, and practice revenue for all physicians and for practice specialties. It frequently reported values for the median, 25th percentile and 7th percentile of physicians nationally. Also, in reporting on regional trends the AMA reported income for all physicians but not for various practice specialties. 
location, physician age, physician gender, and other variables. The surveys include a large enough sample to yield reliable data on trends not only nationally, but within different practice specialties and within nine regions. ${ }^{83}$

Combining data from the AMA's annual reports reveals patterns over time. It can show whether the correlation between premiums and total practice expenses are about the same or whether they have changed. Since the AMA surveys ran from 1970 to 2000, they reveal both short-term and long-term changes as well as any premium cycles within that period. This is important because short-term trends may reveal a different picture than that of a longer term spanning 30 years.

When the AMA advocates for malpractice law change, it is ignoring its own studies. Still, researchers in government and universities consider the AMA practice surveys the gold standard for information on U.S. physicians. The U.S. Department of Health and Human Services and other agencies have relied on this data as have economists, health services researchers, and other scholars. For example, the Medicare Physician Payment Review Commission (PPRC), the Medicare Payment Advisory Commission (MedPAC) and the Department of Health and Human Services Center for Medicare and Medicaid Services (CMS) have all used this data to determine changes in practice expenses (including malpractice premiums) and to revise Medicare physicians' fee-schedules. ${ }^{84}$ When the AMA ended its surveys in 2000, the Medicare program simply adjusted the data for inflation and re-estimated current practice expenses. ${ }^{85}$

\section{A. Adjusting for Inflation}

Comparing income and expenses over time can be misleading if not adjusted for inflation. Older readers of this article will remember when candy bars cost a nickel and Coke cost a dime. Comparing the cost of Coke and candy bars then and now does not reveal real price increases unless they are also compared to price increases of other items. Prices generally rise or fall over time for most goods and services. To learn whether an item costs more now than in the past in

83. The AMA samples were consistently large with small standard deviations. For instance, in 2000, the AMA sample was based on 1,900 completed questioners.

84. See generally Jean M. Mitchell et al., Physicians' Responses to Medicare Fee Schedule Reductions, 38 MED. CARE 1029, 1029 (2000).

85. Medicare Program: Revisions to Payment Policies Under the Physician Fee Schedule, 68 Fed. Reg. 63196, 63240 (Nov.7, 2003) (to be codified at 42 C.F.R. pts. $410 \& 414)$. 
real terms, one needs to distinguish overall price increases from those of the particular item. Economists and statisticians have developed measures that do just that. The Consumer Price Index (CPI) measures inflation for a basket of general consumer goods. One can compare prices from 1970 to 2000 by using the CPI and convert those prices from different years into inflation-adjusted prices for a single year. Here we will report all the AMA data adjusted by the CPI for the year $2005 .{ }^{86}$

Some researchers think that it is more accurate to use a medical inflation index to compare malpractice premiums over time because studies have shown medical expenses increase much more rapidly than prices overall, generally twice the rate of the consumer price index. ${ }^{87}$ However, the most accurate way to measure premium increases is to construct a measure that reflects both the CPI and the medical inflation index but more heavily weighted toward the CPI. Malpractice premiums are used to finance court awards or out of court settlements for physicians who are liable for patient injuries. Such liability includes paying for the injured patient's lost income, the expenses that patients incur due to the injury (such as home care and medical equipment), and the medical costs related to the patient's injury. Court judgments and awards may also compensate patients for pain and suffering, and they may also provide punitive damages, which is essentially a fine against the physician for engaging in reprehensible conduct rather than merely acting negligently. Some of these costs such as lost income are accurately reflected by the CPI. Settlement awards for pain and suffering are frequently a fixed multiple of lost income, typically three times the amount. Since the costs also reflect lost income, CPI also appropriately adjusts them for inflation. Medical expenses, and perhaps home care, however, are probably items best estimated by the medical inflation index rather than the CPI since they are items that tend to increase at the higher medical inflation rate.

86. All dollar figures in this article are expressed in 2005 dollars. We chose to report 2005 dollars because one of the two principle studies from which data is drawn is expressed in 2005 dollars. By reporting the data in 2005 , it is easier to compare our numbers with the other published studies. Readers interested in converting the values that we report in 2005 dollars to 2015 dollars, can do so by multiplying it by 1.20 . They can obtain a CPI index calculator online that will make the conversion for them for any year they choose. See CPI Inflation Calculator, BUREAU OF LABOR STATISTICS, http://www.bls.gov/data/inflation_calculator.htm (last visited Feb. 27, 2015).

87. See Bernard Black et al., Stability, Not Crisis: Medical Malpractice Claim Outcomes in Texas, 1988-2002, 2 J. EMPIRICAL LEGAL Stud. 207, 230 (2005). 
For purposes of this article, premiums are adjusted by the CPI rather than the medical inflation index since there is no index that averages CPI and medical inflation. The CPI is likely to show greater premium increases than the medical inflation index. Since our preliminary analysis of the data found that premiums increased much less than is usually supposed, we wanted to make sure that our methodological choices are not the cause of this unexpected result. We therefore chose the inflation measure that is more likely to exaggerate premium increases.

\section{B. Key AMA Survey Findings}

The surveys reveal four key points: (1) malpractice premiums were always a small portion of total practice expenses; (2) mean malpractice premiums grew modestly over a 30-year span; (3) during that time, other practice expenses increased sharply; and (4) gross practice revenue and net practice income increased from 1975 until 1996, then declined modestly until 2000.

From 1970 to 2000, mean premiums increased modestly for all physicians nationally. But rather than increase steadily, they rose, then fell, and then rose again, thus creating a cycle. Malpractice premiums increased from 1970 until 1986, then declined until 1996 while remaining higher than they were in 1970. Premiums then increased from 1996 until 2000, but were then lower than at their peak in 1986.

Throughout the 30 years, malpractice premiums always represented a small share of total practice expenses. Other practice expenses - including office rent or office building mortgage payments, medical equipment and medical supplies, non-physician salaries, office expenses and utilities ${ }^{8}$ - rose steadily from 1970 to 2000 instead of rising and falling cyclically. These expenses increased by a much larger dollar amount than premiums for the whole period and they surged from 1986 to 2000, years during which premiums declined. As a result, premiums decreased as a percentage of total practice expenses from 1986 to 2000, due in part to declining premium rates and in part due to the surging increases in other practice expenses. Figure 1(a) shows this 30-year trend for all variables and Figure 1(b) shows the trend for malpractice premiums alone with a different scale to make clear small changes that are not visible in Figure 1(a). ${ }^{89}$

88. The AMA did not report details on practice expenses for individual nonpremium expenses in most years. I reported all the details on such individual expenses that I found in the AMA surveys.

89. Data drawn from the AMA surveys as reported in several AMA publications. The data was first analyzed for an article in Health Affairs where it was reported in constant 2000 dollars. In this article all this data has been reported in constant 2005 dollars so that it is comparable 
Figure 1(a). Mean gross revenue, non-premium expenses, malpractice premiums, and net practice income for all self-employed physicians nationally, 1970-2000.

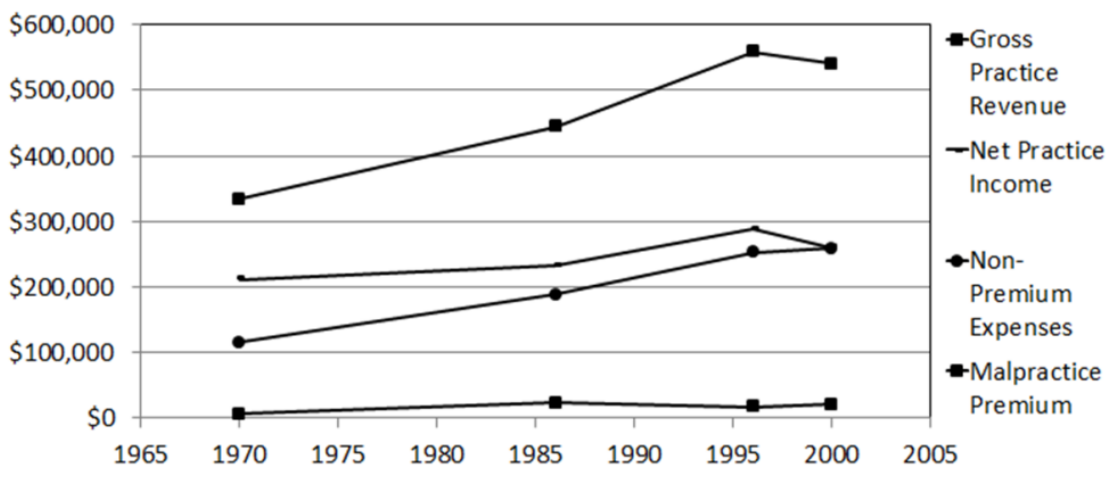

Note: Data adjusted by Consumer Price Index and expressed in constant 2005 dollars.

Figure 1(b). Mean malpractice premiums for all self-employed physicians nationally, 1970-2000.

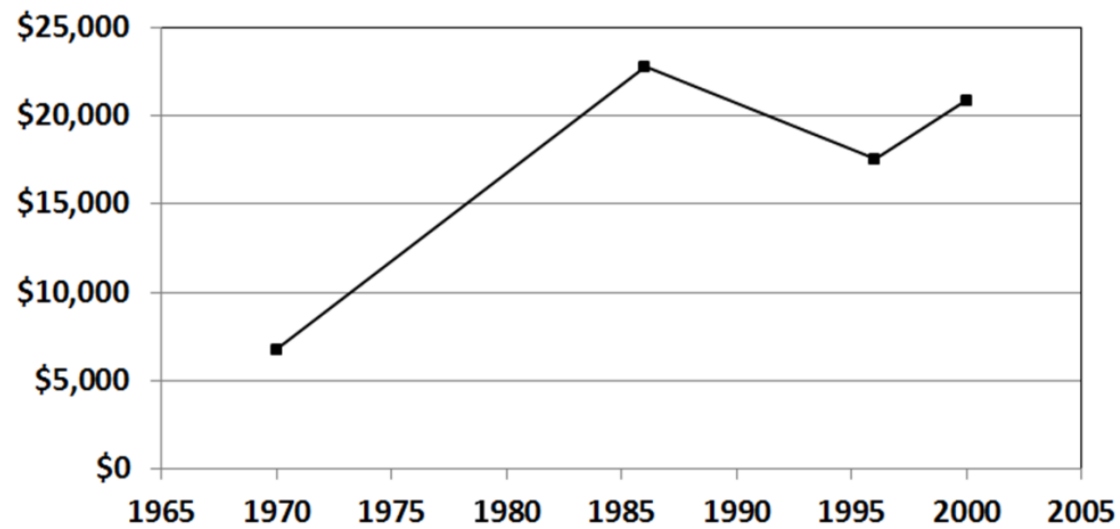

Note: Data adjusted by the Consumer Price Index (CPI) and expressed in constant 2005 dollars.

to the second source of data that I analyze, which was originally reported in constant 2005 dollars. See Marc A. Rodwin et al., Malpractice Premiums in Massachusetts, a High-Risk State: 1975 to 2005, 27 HeAlth AFF. 835, 837 (2008). 
The dollar change in premiums over the 30-year span increases, falls, and then increases again in a cycle, but it still increases in total. Premiums are not large, even at the high points of the premium cycle. Mean premiums increased $\$ 14,138$ from 1970 to 2000 , or $\$ 472$ per year. Premiums declined by $\$ 122$ per year from their 30 -year height in 1986 to 2000 , and at that point were $\$ 1,935$ lower than at their height.

When the AMA and media again proclaimed a malpractice crisis in 2000 , mean premiums were $\$ 20,900$. Of course, the mean values represent the central tendency and individual physicians paid different amounts. Other statistics show variations in the amount physicians paid. The median premium was $\$ 12,500$, meaning that half of all physicians paid less than $\$ 12,500$ and half paid more.

This, according to the AMA, is a crisis. Citing several sources, including its own survey of medical students, the AMA published a report in 2013 detailing what the AMA considered to be an ongoing liability crisis since the mid-2000s..$^{90}$ At this time, according to the report, " 45 percent of hospitals reported that the professional liability crisis resulted in the loss of physicians or reduced coverage in emergency departments." ${ }^{11}$ The "lack of affordable liability insurance" forced 70 percent of OB/GYNs to make changes to their practice and forced 7 to 8 percent of them to stop practicing altogether. ${ }^{92}$ Further, the AMA claimed that medical students are so concerned with their potential liability that many are deciding to avoid high-risk specialties thus contributing to a shortage of physicians in much-needed practices..$^{93}$

Granted, in 2000,25 percent of physicians paid $\$ 22,700$ or more in premiums. But is this really a high amount to pay? So high that doctors are ending their practices en masse and medical students are avoiding certain specialties simply based on the risk associated with practice in that particular specialty? If physicians could cut out $\$ 18,400$ in premium expenses, then that would certainly improve their bottom line and increase their income. But malpractice premiums are a cost of doing business, one which lawyers and other professionals also pay. Of course, malpractice premiums could be less; yet, they cannot be eliminated without removing liability for physicians that are negligent or failing to compensate patients when injured by physician negligence.

\footnotetext{
90. Am. Med. Ass'N, Medical Liability Reform - Now! 10 (2013).

91. Id.

92. Id.

93. Id.
} 
The larger question is this: How do malpractice premiums affect both the cost of running a medical practice and the net practice income? To determine if premiums are a burden on practice profitability, consider the relationship between malpractice premiums and other practice expenses displayed in Figure 2.

Figure 2. Mean malpractice premiums, non-premium expenses, and total practice expenses for all self-employed physicians nationally, 1970-2000 including dollar changes for selected periods.

\begin{tabular}{|c|c|c|c|c|c|c|c|}
\hline & 1970 & 1986 & 1996 & $\mathbf{2 0 0 0}$ & $\begin{array}{c}\text { \$Change } \\
\mathbf{1 9 9 6 - 2 0 0 0}\end{array}$ & $\begin{array}{c}\mathbf{\$} \text { Change } \\
\mathbf{1 9 8 6 - 2 0 0 0}\end{array}$ & $\begin{array}{c}\text { \$Change } \\
\mathbf{1 9 7 0 - 2 0 0 0}\end{array}$ \\
\hline $\begin{array}{c}\text { Non- } \\
\text { Premium } \\
\text { expenses }\end{array}$ & $\$ 115,589$ & $\$ 188,127$ & $\$ 253,349$ & $\$ 258,812$ & $\$ 5,463$ & $\$ 70,686$ & $\$ 143,223$ \\
\hline $\begin{array}{c}\text { Malpractice } \\
\text { Premium }\end{array}$ & $\$ 6,730$ & $\$ 22,803$ & $\$ 17,554$ & $\$ 20,868$ & $\$ 3,314$ & $(\$ 1,935)$ & $\$ 14,139$ \\
\hline $\begin{array}{c}\text { Total } \\
\text { Expenses }\end{array}$ & $\$ 122,319$ & $\$ 210,930$ & $\$ 270,903$ & $\$ 279,680$ & $\$ 8,777$ & $\$ 68,751$ & $\$ 157,362$ \\
\hline
\end{tabular}

Note: Data adjusted by the CPI and expressed in constant 2005 dollars.

Annual mean medical malpractice premiums were consistently a small fraction of total practice expenses. Premiums ranged from $\$ 6,730$ to $\$ 22,803$, while total practice expenses ranged from $\$ 122,319$ to $\$ 279,680$. From 1970 to 2000 , mean premiums increased $\$ 14,139$ while non-premium expenses increased $\$ 143,223 .{ }^{94}$

Again, the changes were not uniform over the entire survey period. Malpractice premiums declined, from 1986 to 1996, while spending on other practice expenses increased substantially. Nonpremium expenses increased from $\$ 188,127$ to $\$ 253,349$, by $\$ 65,222$, or 34 percent. Office expenses increased from $\$ 50,772$ to $\$ 64,489$ or 27 percent; and non-physician personnel expenses increased from $\$ 69,148$ to $\$ 4,243$ or 36 percent. Spending on rent, medical equipment, and supplies, furniture, and utilities also increased sharply..$^{95}$

The ratio of premiums to total practice expenses are displayed in Figure 3. The dollar figures are for total practice expenses.

94. From 1986 to 2000 , total mean premiums declined by $\$ 1,935$ while total non-premium expenses increased $\$ 70,584$.

95. The AMA distinguished between office expenses and furniture, supplies and utilities. The AMA included items other than these for office supplies. 
Malpractice premiums as a percentage of total expenses are shown on the top of each bar.

Figure 3. Mean medical malpractice premiums and non-premium expenses for self-employed physicians surveyed by the AMA, selected years 1970-2000.

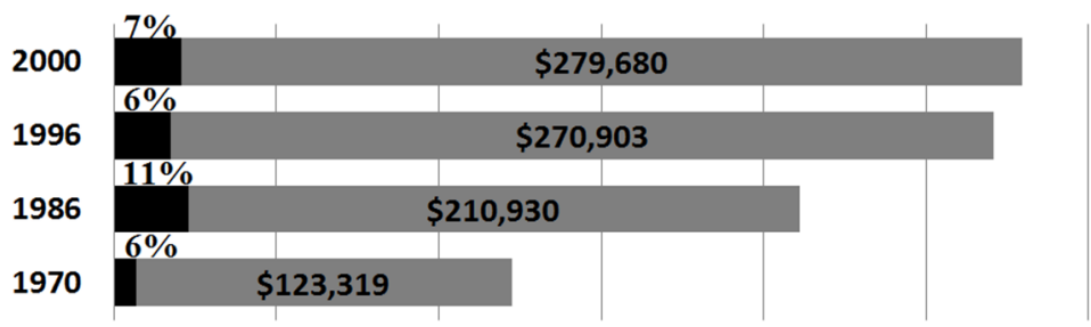

- Malpractice Premiums non-Premium Expenses

Note: Mean total expenses are shown in the bar graph. Data adjusted by the CPI and expressed in constant 2005 dollars.

Malpractice premiums represented 6 percent of total practice expenses in 1970 and 1996, the two years when premiums represented the smallest share of total practice expenses. In 1986, premiums comprised 11 percent of total practice expenses, the highest percentage in the survey. But by 2000, premiums as a percentage of total practice expenses dropped to 7 percent, hardly more than their lowest point in the survey.

Consider now how premium increases affected net practice income. Figure 4 uses bar charts to compare gross practice revenue, malpractice premiums, non-premium expenses, and net practice income in 1970, 1986, 1996, and 2000. Figure 5 displays the dollar amount for these variables and the dollar changes for each variable in three periods. 
Figure 4. Mean practice revenue, non-premium expenses, malpractice premiums and net practice income for all self-employed physicians nationally, 1970-2000.

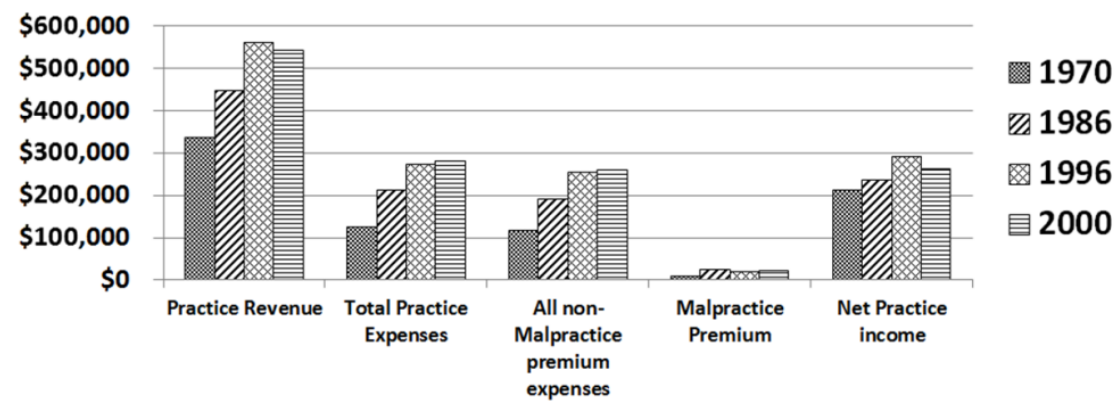

Note: Data adjusted by Consumer Price Index and expressed in constant 2005 dollars.

In reviewing practice expenses, keep in mind that mean net practice income increased from $\$ 211,535$ in 1970 to $\$ 260,287$ in 2000 , representing a total increase of $\$ 48,752$, or $\$ 1,625$ per year over 30 years. When premiums increased between 1970 and 1986, they had only a small effect on net income. While premiums increased by $\$ 16,073$, that increase was only a fraction of the $\$ 72,538$ increase for non-premium expenses; and despite increases in total practice expenses, net income increased by $\$ 22,019$. When premiums declined $\$ 1,935$ from 1986 to 2000, non-premium expenses increased by $\$ 70,686$.

From 1996 to 2000, physicians' net practice income fell nationally. This was primarily due to decreased gross practice revenue. Revenue decreased $\$ 4,817$ per year during that four-year period, which is nearly six times as great as the $\$ 829$ premium increase per year during that same period. Also, between 1996 and 2000, non-premium expenses increased $\$ 1,366$ per year. 
Figure 5. Mean gross practice revenue, non-premium expenses, malpractice premiums and net practice income, 1970-2000 including the dollar change for each variable and selected periods.

\begin{tabular}{|l|r|r|r|r|r|r|r|}
\hline & $\mathbf{1 9 7 0}$ & $\mathbf{1 9 8 6}$ & $\mathbf{1 9 9 6}$ & $\mathbf{2 0 0 0}$ & $\begin{array}{l}\text { S Change } \\
\mathbf{1 9 9 6 - 2 0 0 0}\end{array}$ & $\begin{array}{l}\text { S Change } \\
\mathbf{1 9 8 6 - 2 0 0 0}\end{array}$ & $\begin{array}{l}\text { S Change } \\
\mathbf{1 9 7 0 - 2 0 0 0}\end{array}$ \\
\hline $\begin{array}{l}\text { All } \\
\text { Physicians } \\
\text { Practice } \\
\text { Revenue }\end{array}$ & $\$ 333,854$ & $\$ 444,484$ & 559,236 & $\$ 539,967$ & $(\$ 19,269)$ & $\$ 95,483$ & $\$ 206,113$ \\
\hline $\begin{array}{l}\text { Total } \\
\text { Practice } \\
\text { Expenses }\end{array}$ & $\$ 122,319$ & $\$ 210,930$ & $\$ 270,903$ & $\$ 279,680$ & $\$ 8,777$ & $\$ 68,751$ & $\$ 157,362$ \\
\hline $\begin{array}{l}\text { Non- } \\
\text { Malpractice } \\
\text { expenses }\end{array}$ & $\$ 115,589$ & $\$ 188,127$ & $\$ 253,349$ & $\$ 258,812$ & $\$ 5,463$ & $\$ 70,686$ & $\$ 143,223$ \\
\hline $\begin{array}{l}\text { Malpractice } \\
\text { Premiums }\end{array}$ & $\$ 6,730$ & $\$ 22,803$ & $\$ 17,554$ & $\$ 20,868$ & $\$ 3,314$ & $(\$ 1,935)$ & $\$ 14,139$ \\
\hline $\begin{array}{l}\text { Net Practice } \\
\text { Income }\end{array}$ & $\$ 211,535$ & $\$ 233,555$ & $\$ 288,333$ & $\$ 260,287$ & $(\$ 28,046)$ & $\$ 26,732$ & $\$ 48,751$ \\
\hline
\end{tabular}

Note: Data adjusted by the CPI and expressed in constant 2005 dollars.

The data on mean premiums for physicians nationally and across practice specialties does not support claims of a premium crisis around the year 2000. If there was a crisis, it appeared to be around 1986, the peak year for premiums. But even then, premiums were a small part of total practice expenses. No doubt physicians felt a financial pinch, but it was not because of the premiums they paid. When compared to other expenses, premiums were not the dire problem as described by many physicians and politicians.

\section{A Crisis Within Selected Practice Specialties?}

Might some medical specialties face a premium crisis not reflected in average rates for all physicians? In theory it is possible, but the data do not show this to be the case.

Specialties paying the highest premiums include obstetrics, neurosurgery, orthopedics, and until 1990, anesthesiology. The AMA reports data for all of these specialties except neurosurgery, which was still developing as a practice specialty when the surveys began in 1970 and is thus not included as a practice category in the data. A review of the AMA data shows that the specialty with the highest premiums is Obstetrics/Gynecology (OB/GYN) followed by orthopedic surgery. The specialties with the highest premiums are most likely to experience a crisis, so let us look at the at the AMA data to see if they did.

Figure 6 uses a line graph to display the relationship among gross revenue, non-premium expenses, premiums, and net practice income nationwide for OB/GYNs from 1970 to 2000. Figure 7 displays the dollar values for these variables and the dollar value of change for 
three periods. Figure 8 shows as a bar graph the relation among gross practice revenue, non-premium expenses, premiums and net practice income in three periods.

OB/GYNs reflect the basic trend of all physicians in terms of premiums paid, premium cycles, and total practice expenses. Their premium rates increased moderately over thirty years while nonpremium expenses increased sharply. Premiums for OB/GYNs - the highest of any specialty - were always a small fraction of total practice expenses; they were as low as 8 percent of total practice expenses in 1970 and as high as 20 percent in 1986. Premiums fell thereafter until 1996 and then increased until 2000 when they comprised 13 percent of total practice expenses or $\$ 44,459$. From 1986 to 2000 , OB/GYN premiums decreased $\$ 7,739$ or $\$ 553$ per year while non-premium practice expenses increased $\$ 91,970$ or $\$ 6,569$ per year.

Despite having the highest malpractice premiums, OB/GYN net mean practice income was consistently higher than mean net physician income. Although OB/GYN net income decreased from its high of $\$ 302,401$ in 1996 , it was $\$ 275,484$ in 2000 when mean practice income for all physicians was $\$ 260,287$. Malpractice premiums did not appear to create an OB/GYN crisis.

Figure 6. Mean gross revenue, non-premium expenses, malpractice premiums and net practice income for all self-employed OB/GYNs nationally, 19702000 .

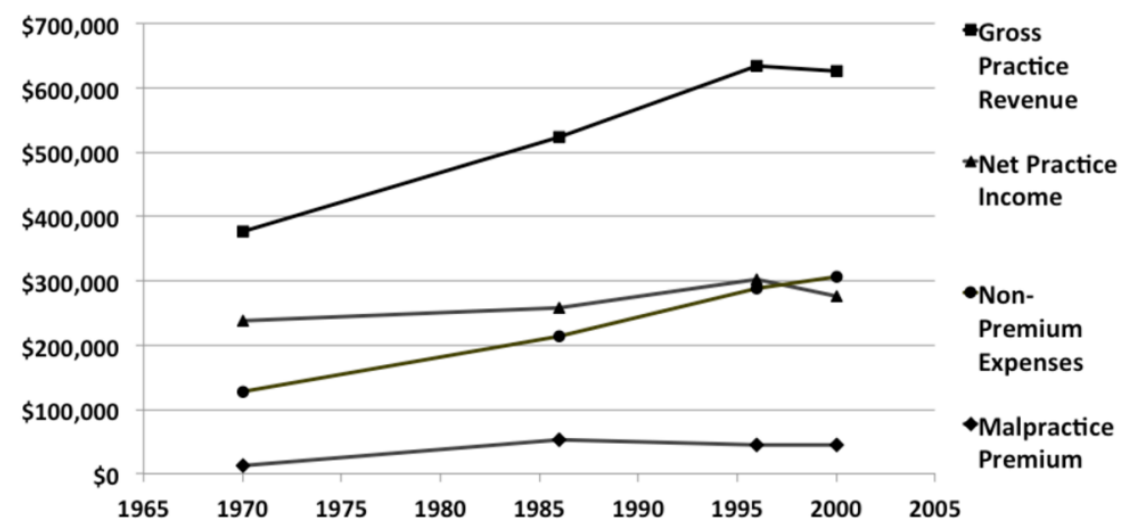

Note: Data adjusted by the CPI and expressed in constant 2005 dollars. 
Figure 7. Mean gross revenue, non-premium expenses, malpractice premiums and net practice income for all self-employed OB/GYNs nationally, 1970-2000 including the dollar change for each variable and for selected periods.

\begin{tabular}{|c|c|c|c|c|c|c|c|}
\hline & 1970 & 1986 & 1996 & 2000 & $\begin{array}{l}\text { S Change } \\
1996-2000\end{array}$ & $\begin{array}{l}\text { \$Change } \\
1986-2000\end{array}$ & $\begin{array}{l}\text { s Change } \\
1970-2000\end{array}$ \\
\hline $\begin{array}{l}\text { OB/GYN } \\
\text { Practice } \\
\text { Revenue }\end{array}$ & $\$ 376,512$ & $\$ 523,761$ & $\$ 634,930$ & $\$ 626,049$ & $(\$ 8,882)$ & $\$ 102,288$ & $\$ 249,537$ \\
\hline $\begin{array}{c}\text { Total } \\
\text { Practice } \\
\text { Expenses }\end{array}$ & $\$ 139,433$ & $\$ 266,334$ & $\$ 332,529$ & $\$ 350,565$ & $\$ 18,035$ & $\$ 84,231$ & $\$ 211,132$ \\
\hline $\begin{array}{c}\text { All Non- } \\
\text { Malpractice } \\
\text { Premium } \\
\text { Expenses }\end{array}$ & $\$ 127,720$ & $\$ 214,136$ & $\$ 288,707$ & $\$ 306,106$ & $\$ 17,399$ & $\$ 91,970$ & $\$ 178,386$ \\
\hline $\begin{array}{l}\text { Malpractice } \\
\text { Premiums }\end{array}$ & $\$ 11,713$ & $\$ 52,198$ & $\$ 43,822$ & $\$ 44,459$ & $\$ 636$ & $(\$ 7,739)$ & $\$ 32,745$ \\
\hline $\begin{array}{c}\text { Net } \\
\text { Practice } \\
\text { Income }\end{array}$ & $\$ 237,09$ & $\$ 257,427$ & $\$ 302,401$ & $\$ 275,484$ & $(\$ 26,917)$ & $\$ 18,057$ & $\$ 38,406$ \\
\hline
\end{tabular}

Note: Data adjusted by the CPI and expressed in constant 2005 dollars.

Figure 8. Mean practice revenue, non-premium expenses, malpractice premiums and net practice income for all self-employed OB/GYNs nationally, 1970-2000.

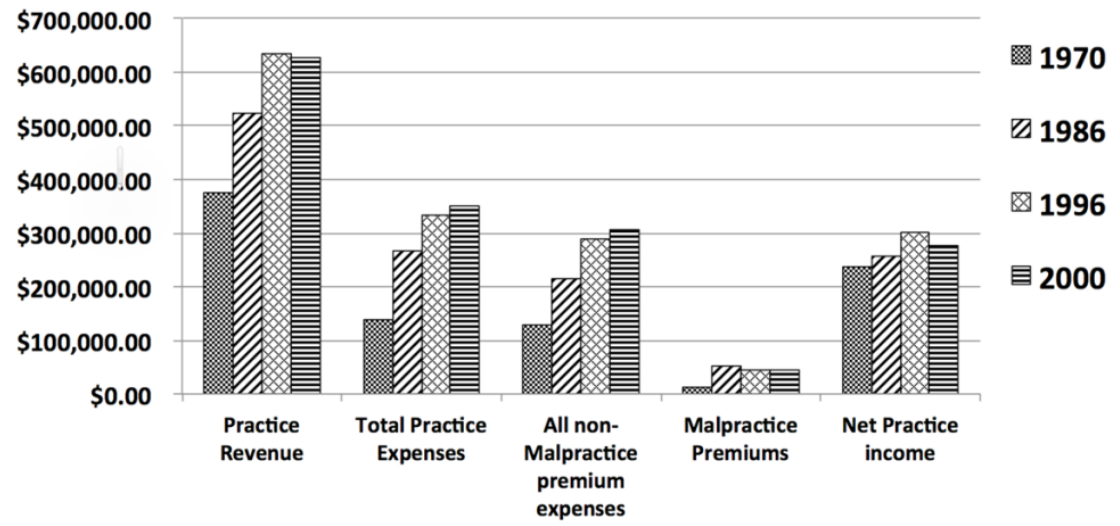

Note: Data adjusted by the CPI and expressed in constant 2005 dollars.

\section{A Crisis Among Physicians Paying Higher Than Mean Premiums?}

A review of data for the 75th percentile shows that premiums were no greater a share of total expenses for physicians within that top quartile than for the mean. In 2000, premiums represented either the same percentage of total expenses at the 75th percentile as at the mean or a lower percentage of total expenses. This is true both as a 
whole nationally and specifically for OB/GYNs. In 1986 and 1996, the relationship among these variables was similar; median values were within two points of the mean for all physicians and within three points for OB/GYNs.

Expressed in 2005 dollars, median premiums in 2000 were $\$ 12,476$ with the top quartile of physicians paying $\$ 22,683$ or more. If these physicians had other practice expenses and revenue that were in the top quartile, their higher premiums would not have resulted in lower net practice income than most physicians; indeed, net practice income for the top quartile of physicians was at or above $\$ 340,244$.

But physicians who paid higher than mean premiums while also having other expenses and net revenue at the mean level would have had lower than mean net income. For example, consider a physician who, in 2000, generated median revenue and had median nonpremium practice expenses while paying premiums at the 75 th percentile for self-employed physicians, $\$ 22,683$. This physician would pay $\$ 10,207$ more in premiums than the median of $\$ 12,476$. As a result, this physician's net income would decrease from the median of $\$ 226,829$ to $\$ 216,622$. Although that physician would earn less that many others, there still does not appear to be an excessive burden imposed by the premium costs.

\section{E. A Crisis Within Specific Regions?}

It is possible that there are regional premium crises that are not reflected in national data because the national data simply averages all regions together. Many factors affect the local cost of premiums. For instance, state insurance regulations can affect premiums. State laws, medical practice, and even culture can affect the rate of negligent practice, the propensity of individuals to bring suits, and the amount of awards. Groups advocating legislation that caps the amount of money patients can recover say that legislation will reduce malpractice practice premiums, and consequently, the size of awards. About half of U.S. jurisdictions have some sort of caps on malpractice awards, so these states may have lower premiums than states without caps. $^{96}$

Of those states without caps, some are currently considering legislation that would reduce the size of awards, and consequently, the price of premiums. Hawaii legislators, for example, proposed a bill that would limit non-economic damages in medical tort actions,

96. Kenneth E. Thorpe, The Medical Malpractice 'Crisis': Recent Trends and the Impact of State Tort Reforms, 2004 HEALTH AFF. W4-20, w4-26 (2004); see also Medical Liability/Medical Malpractice Laws, NAT'L CONF. OF ST. LEgislature (Aug. 15, 2011), available at http://www.ncsl.org/research/financial-services-and-commerce/medicalliability-medical-malpractice-laws.aspx. 
contingent on insurers capping their premium rates. ${ }^{97}$ The legislation, which was not enacted, would have limited all non-economic damages in medical tort actions to a maximum award of $\$ 500,000$. Meanwhile, Virginia legislators have questioned whether their current cap on medical liability is low enough to adequately deter defensive practices. ${ }^{98}$

National data does not necessarily reflect these efforts to limit liability, but instead provides statistics representing an average of all states. There is potential for those states with escalating premiums to overshadow the many more states with more reasonable rates or statutory limits on liability. Perhaps, one may argue, if not a national crisis, there exists a regional one. Unfortunately, AMA publications do not include state specific data, probably because the sample size was not large enough to yield reliable statistics for each state. But the surveys do include data for nine regions. Figure 9 displays regional and national mean dollars for all variables from 1986 to 2000. It also shows premiums as a percentage of these variables.

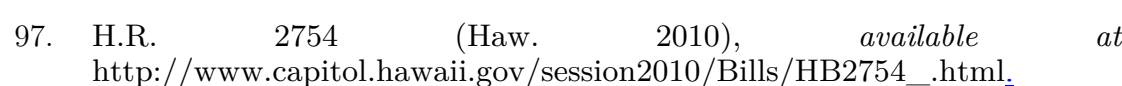

98. H.R. Res. 14, 2010 Sess (Va. 2010), available at http://leg1.state.va.us/cgi-bin/legp504.exe?101+ful+HJ14. 
Figure 9. Self-employed physicians: regional variations in mean malpractice premiums, total expenses, net income; premiums as a percentage of total expenses and new income, selected years 1986-2000.

\begin{tabular}{|c|c|c|c|c|c|c|c|c|c|c|c|c|}
\hline \multicolumn{3}{|c|}{ New England } & \multicolumn{2}{|c|}{$\begin{array}{c}\text { Middle } \\
\text { Atlantic } \\
\end{array}$} & \multicolumn{2}{|c|}{$\begin{array}{c}\text { East North } \\
\text { Central }\end{array}$} & \multicolumn{2}{|c|}{$\begin{array}{c}\text { West North } \\
\text { Central } \\
\end{array}$} & & & \multicolumn{2}{|c|}{ National } \\
\hline & $\mathbf{\$ A}$ & $\% \mathbf{B}$ & $\mathbf{\$ A}$ & $\% \mathbf{B}$ & $\mathbf{\$ A}$ & $\%$ B & $\mathbf{\$ A}$ & $\% \mathrm{~B}$ & & & \$B & $\% B$ \\
\hline \multicolumn{13}{|c|}{ Medical Malpractice Premiums } \\
\hline 1986 & 19.1 & - & 26.5 & - & 23.8 & - & 24.3 & - & & & & \\
\hline 1996 & 17.9 & - & 22.1 & - & 21.1 & - & 14.3 & - & & & & \\
\hline 2000 & 14.4 & - & 26.3 & - & 21.2 & - & 17.2 & - & & & & \\
\hline \multicolumn{13}{|c|}{ Total Expenses } \\
\hline 1986 & 168.5 & $11 \%$ & 187.8 & $14 \%$ & 189.4 & $13 \%$ & 236.2 & $10 \%$ & & & 211 & $11 \%$ \\
\hline 1996 & 211.1 & $8 \%$ & 248.7 & $9 \%$ & 262.8 & $8 \%$ & 275.3 & $5 \%$ & & & 270.9 & $6 \%$ \\
\hline 2000 & 298.7 & $5 \%$ & 267.3 & $10 \%$ & 291.2 & $7 \%$ & 223.2 & $8 \%$ & & & 280.1 & $7 \%$ \\
\hline \multicolumn{13}{|c|}{ Net Income } \\
\hline 1986 & 206 & $9 \%$ & 222.3 & $12 \%$ & 251.6 & $9 \%$ & 229.7 & $11 \%$ & & & 233.5 & $10 \%$ \\
\hline 1996 & 242.1 & $6 \%$ & 288 & $8 \%$ & 285.4 & $7 \%$ & \begin{tabular}{|l|}
313.9 \\
\end{tabular} & $5 \%$ & & & 288.3 & $6 \%$ \\
\hline \multirow[t]{3}{*}{2000} & 222.1 & $7 \%$ & 229.3 & $11 \%$ & 241.7 & $9 \%$ & 236.4 & $7 \%$ & & & 260.3 & $8 \%$ \\
\hline & \multicolumn{2}{|c|}{$\begin{array}{c}\text { South } \\
\text { Atlantic }\end{array}$} & \multicolumn{2}{|c|}{$\begin{array}{c}\text { East South } \\
\text { Central }\end{array}$} & \multicolumn{2}{|c|}{\begin{tabular}{|c|}
$\begin{array}{c}\text { West South } \\
\text { Central }\end{array}$ \\
\end{tabular}} & \multicolumn{2}{|c|}{ Mountain } & \multicolumn{2}{|c|}{ Pacific } & \multicolumn{2}{|c|}{ National } \\
\hline & $\mathbf{\$ A}$ & $\% \mathrm{~B}$ & $\mathbf{S A}$ & $\% \mathrm{~B}$ & $\mathbf{\$ A}$ & $\%$ B & \$A & $\% \mathrm{~B}$ & \$A & $\% \mathrm{~B}$ & \$A & $\% A$ \\
\hline \multicolumn{13}{|c|}{ Medical Malpractice Premiums } \\
\hline 1986 & 25.6 & - & 18 & - & 14.4 & - & 21.3 & - & 22.8 & - & 22.8 & \\
\hline 1996 & 16.2 & - & 15.7 & - & 14.3 & - & 18.7 & - & 14.7 & - & 17.6 & \\
\hline 2000 & 21.4 & - & 23.3 & - & 17.7 & - & 21.8 & - & 16.7 & - & 20.9 & \\
\hline \multicolumn{13}{|c|}{ Total Expenses } \\
\hline 1986 & 233.1 & $11 \%$ & 236.9 & $8 \%$ & 247.5 & $6 \%$ & 186.3 & $11 \%$ & 209.5 & $11 \%$ & 211 & $11 \%$ \\
\hline 1996 & 325.3 & $5 \%$ & 298.7 & $5 \%$ & 266.9 & $5 \%$ & 278.9 & $7 \%$ & 247.1 & $6 \%$ & 270.9 & $6 \%$ \\
\hline 2000 & 280.9 & $8 \%$ & 296.1 & $8 \%$ & 269.2 & $7 \%$ & 264.6 & $8 \%$ & 297.3 & $6 \%$ & 280.1 & $7 \%$ \\
\hline \multicolumn{13}{|c|}{ Net Income } \\
\hline 1986 & 239.4 & $11 \%$ & 250.3 & $7 \%$ & 249.7 & $6 \%$ & 208.8 & $10 \%$ & 225.7 & $10 \%$ & 233.5 & $10 \%$ \\
\hline 1996 & 294.2 & $6 \%$ & 335.9 & $5 \%$ & 299.9 & $5 \%$ & 295.1 & $6 \%$ & 262.2 & $6 \%$ & 288.3 & $6 \%$ \\
\hline 2000 & 230.9 & $9 \%$ & 258.4 & $9 \%$ & 256.5 & $7 \%$ & 223.8 & $10 \%$ & 215.6 & $8 \%$ & 260.3 & $8 \%$ \\
\hline
\end{tabular}

Note: Data adjusted by Consumer Price Index to constant 2005 dollars.

\$A: Thousand dollars;

\%B: Premiums as a percentage of the variable (total expenses, net income, or revenue) in the year shown in column 1. 
The nine regions reflected national trends with only slight variations. ${ }^{99}$ Premiums decreased between 1 and 41 percent in the regions from 1986 to 1996, then increased until 2000 in all regions except New England. Premiums in 2000 were less than 1986 levels in six regions and above those levels in three regions. The highest increases were in the East South Central region.

In 2000, premiums were highest in the Middle Atlantic. At $\$ 26,300$, this was $\$ 5,400$ more than the national mean. But Middle Atlantic premiums were then less than in 1986 and represented less than 10 percent of total practice expenses. In 2000, physician net income in the Middle Atlantic region was $\$ 253,400$, nearly $\$ 7,000$ less than the national mean of $\$ 260,300$. Three regions with premiums lower than the Middle Atlantic region, however, had lower net income-New England, Mountain and Pacific.

Nationally, premiums constituted 11 percent of total practice expenses at their height in 1986 and 6 percent in 1996, when at their lowest. Premiums ranged within regions from 14 percent of expenses in 1986 in the Middle Atlantic to 5 percent of expenses in 2000 in New England. Though the data does not provide a complete picture of potential regional crises, the most telling statistic may be the following: Regional premiums as a percentage of total practice expenses were never more than 3 points higher than the national mean in any of the years surveyed.

\section{F. Can AMA Data Be Interpreted to Suggest a Crisis Exists?}

Premium increases since 1996 must be considered in light of premium decreases for the 14 preceding years prior to 2000. Rates were lower in 2000 than in 1986 for all physicians nationally, for OB/GYNs (the highest premium practice specialty) and for the Middle Atlantic Region (the highest premium region).

Nonetheless, viewed impartially and uncritically, the AMA data can support the perception that premium increases resulted in a decline in physician income. The surveys show that while premiums increased by $\$ 3,314$ from 1996 to 2000, many physicians' income declined. ${ }^{100}$ These trends alone might lead casual observers to conclude that premium increases actually caused the income decline.

99. The New England region: Massachusetts, New Hampshire, Vermont, Maine; the Pacific region: California, Oregon and Washington; the Mountain region: Montana, Idaho, Colorado, Wyoming; the Middle Atlantic region: New Jersey, New York, Pennsylvania, Delaware; the East North Central region: Illinois, Michigan, Ohio, Wisconsin; the West North Central region: Minnesota; the South Atlantic region: Florida; the East South Central region: Louisiana, Mississippi; and the West South Central region: Texas.

100. Supra Figure 2 . 
Armed with this anecdotal evidence, the national media ran with that story for several years. "Dr. David Snyder is calling it quits," began a 2003 article in the Pittsburgh Business Times. ${ }^{101}$ "After practicing in Beaver County for 12 years, the escalating malpractice premiums have forced the 55-year-old general surgeon to an abrupt stop." 102 Said Snyder, "I can't ignore the economics of my situation." 103

Despite some doctors' difficulties, a different economic picture emerges when other data are examined. From 1996 until 2000, nonpremium expenses increased for physicians nationally by $\$ 5,463 .{ }^{104}$ Furthermore, mean gross practice revenue declined for physicians nationally by $\$ 19,269 .{ }^{105}$ As a result, net practice income fell by $\$ 28,046{ }^{106}$ It was declining revenue combined with increasing nonpremium expenses that caused the overwhelming share of declining net practice income - not malpractice premiums. Increasing insurance rates were responsible for at most 12 percent of the decline in net income - in many cases, much less.

The situation is similar, if not more dramatic, for OB/GYNs. From 1996 to 2000, OB/GYN mean premiums increased by $\$ 636$, but non-premium expenses increased by $\$ 17,399 .{ }^{107}$ Increases in nonpremium expenses were more than 27 times the size as increase in premiums. During this period, gross practice revenue also decreased by $\$ 8,882$. As a result, increasing malpractice premiums constituted less than 2.5 percent of the decline in net income.

In the Middle Atlantic Region, from 1996 to 2000, mean premiums increased by $\$ 4,200$ but non-premium expenses increased even more, by $\$ 14,400 .{ }^{108}$ Gross practice revenue also decreased by $\$ 34,600$. Here too, decreases in gross practice revenue and increases in non-premium expenses accounted for the overwhelming share of decreased net practice income. Increased malpractice premiums accounted for just under 12 percent of decreased physician income.

101. Maria Simbra, Disappearing Doctors - The High Cost of Rising Malpractice Premiums, PitTsburgh Business Times (Jan. 27, 2003), http://www.bizjournals.com/pittsburgh/stories/2003/01/27/focus4.html ?page $=$ all.

102. Id.

103. Id.

104. Supra Figure 2.

105. Supra Figure 5.

106. Supra Figure 5.

107. Supra Figure 7.

108. Supra Figure 9. 
In summary, although the AMA and many physicians might blame premiums for their declining income from 1996 to 2000, the overwhelming share of falling net practice income came through the combination of declining gross practice revenue and increasing nonpremium expenses.

Why did physician revenue decline? The AMA data cannot answer that question. Separate studies suggest that third-party payers reduced physician fees and made physicians bear financial risk for the volume of services they supplied or recommended. ${ }^{109}$ Writing in 1992, Gregory Pope and John E. Schneider, economists at the Center for Health Economics Research in Waltham, Massachusetts, wrote, "Rapid physician income growth in the 1980s suggests that it would not impose a financial hardship, on average, for physicians to contribute to federal deficit reduction through lower Medicare fees." ${ }^{110}$ In fact, Medicare did reduce physician payment.

Insurers appear to have reduced the volume of services that physicians performed by employing managed care techniques such as requiring authorization for elective surgery, limiting access to specialists and other utilization management techniques. By reducing the volume of services which physicians would be reimbursed, they reduced physician income.

109. A report by the Center for Studying Health System Change reveals that between 1995 and 2003 physician net income from medical practice declined $7 \%$ after adjusting for inflation and that the major factor was "flat or declining fees from public and private payers." HA T. TU \& Paul B. Ginsburg, Ctr. for Studying Health Sys. Change, Losing Ground: Physician Income, 1995-2003 3 (2006). A study by professor Carol Simon, University of Illinois, and Patricia Born, an economist at the American Medical Association Center for Health Policy Research, shows that physician income declined from 1993 to 1994. They state that the "[d]ata . . . are generally consistent with the hypothesis that managed care shifted the demand for physician services toward primary care providers while reducing utilization, fees, or both to physicians." Carol J. Simon \& Patricia H. Born, Physician Earnings in a Changing Managed Care Environment, 15 HeAlth AFF. 124, 127 (1996). The role of physician risk sharing and capitation is noted in Carol J. Simon \& David W. Emmons, Physician Earnings at Risk: An Examination of Capitated Contracts, 16 HeAlth AFF. 120, 120 (1997); see also Marsha R. Gold et al., A National Survey of the Arrangements Managed-Care Plans Make with Physicians, 333 NEJM 1678, 1678 (1995).

110. Gregory C. Pope \& John E. Schneider, Trends in Physician Income, 11 HEALTH AFF. 181, 191 (1992) (finding that "physicians' real income rose handsomely in the late 1980s.") Id. at 184. The authors concluded that the "[p]rovision of more services and higher profit per service contributed roughly equally to physician income growth in the 1980s." Id. at 188. The authors found that between 1982 and $1988,42 \%$ of the growth of income was due to increased services and that $58 \%$ due to higher unit-profit margin. Id. at 188. 
While the AMA surveys may startle many readers because they contradict the statements of the AMA political campaigns to cap malpractice premiums, other AMA reports show that the AMA accepts the findings of its surveys, even though it takes a different stance in public. For instance, a 2002 AMA report stated that "average premiums across all specialties and geographical regions declined from $\$ 15,900$ in 1988 to $\$ 13,800$ in 1992 , and then rose to a new high of $\$ 16,800$ in 1998." 111 However, the report continued by adding, "in inflation adjusted dollars, malpractice premiums declined 30.3\% between 1988 and 1998." 112

Unfortunately, the AMA ended its surveys in 2000. What then can be said about premiums since then? The AMA surveys reveal cyclical premium increases and decreases since 1970, rather than steady increases. There is no reason to believe that the short-term premium increases that began in 1996 will not later decline or that they will affect the long-term cyclic trends previously identified.

Furthermore, the AMA surveys are in line with other reliable data. Information published by the federal government to explain the basis of its Medicare physician fee-schedule indicates that, despite increases in malpractice premiums after 2000, premiums as of midyear 2003 remained a small fraction of total practice expenses.

The Center for Medicare and Medicaid Services (CMS), which administers Medicare, adjusts physician payment periodically based on changes in practice costs and other variables. At least in this respect, claims of burdensome premium payments are less credible when CMS explicitly adjusts fees to account for changes in the cost of medical malpractice insurance. In addition, the amounts that Medicare pays physicians are adjusted regionally to account for differences in malpractice premiums and other costs.

The basis for CMS's conclusions on malpractice premiums, additional practice costs, and other aspects of its proposed fee schedule are published in the Federal Register. Affected parties can comment on the proposed fee schedule. Because the fee schedule is important for Medicare payments and because private insurers also use the fee schedule as a model, professional medical groups submit detailed comments. CMS must take account of comments on its proposed fee schedule in promulgating a final Medicare fee schedule. CMS publishes responses to comments that explain the basis for its

111. American Med. Assoc., Ama Council on Medical Services, CMS RePort 12: Liability InSURANCE PREMiUms (2002) (noting the number in this AMA document are as reported and have not been converted in 2005 dollars) (on file with the author).

112. Id. (emphasis added). 
final decision. If CMS does not adequately respond to any criticism via these comments, affected parties can sue the agency in federal court. If a court finds that the CMS fee schedule is arbitrary and capricious or against the weight of evidence, the court can overturn the fee-schedule.

In the fall of 2003, CMS revised the weights that it uses to determine the cost of medical practice for the Medicare fee-schedule to take effect in January 2004. CMS revised the fee schedule to take account of data on increased medical malpractice premiums through mid-year 2003. ${ }^{113}$ It also projected additional premium increases into $2004 .{ }^{114}$

In proposing another revision of physician fees in July 2007 to take effect the following year, CMS has used the same weights for malpractice premiums. ${ }^{115}$ Using the same AMA data used in this article, and numerous other sources, CMS found that premiums had increased from 3.152 percent of gross practice revenue in 1996 to 3.865 percent of gross practice revenue in 2004. ${ }^{116}$ This represented nearly a 17 percent increase in the weight assigned to malpractice premiums as a factor in physician practice costs. The CMS findings regarding the relationship between malpractice premiums and gross practice revenue are displayed in the pie-chart below in Figure 10(a).

113. Medicare Program: Revisions to Payment Policies Under the Physician Fee Schedule for Calendar Year 2004, 68 Fed. Reg. 63,196, 63,213 (Nov. $7,2003)$.

114. Id.

115. See Medicare Program: Proposed Revisions, 72 Fed. Reg. 38,122 (July 12, 2007) (to be codified at 42 C.F.R. pts. 409, 410, 411, 413, 414, 415, 418, 423, 424, 482, 484, 485 and 491).

116. Medicare Program; Proposed Revisions to Payment Policies Under the Physician Fee Schedule for Calendar Year 2004, 68 Fed. Reg. 63,196, 63,240 (Nov. 7, 2003) (to be codified at 42 C.F.R. pts. 410 and 414). 
Figure 10(a). Allocation of gross practice revenue for physicians nationally, 2004, as determined by Medicare. ${ }^{117}$

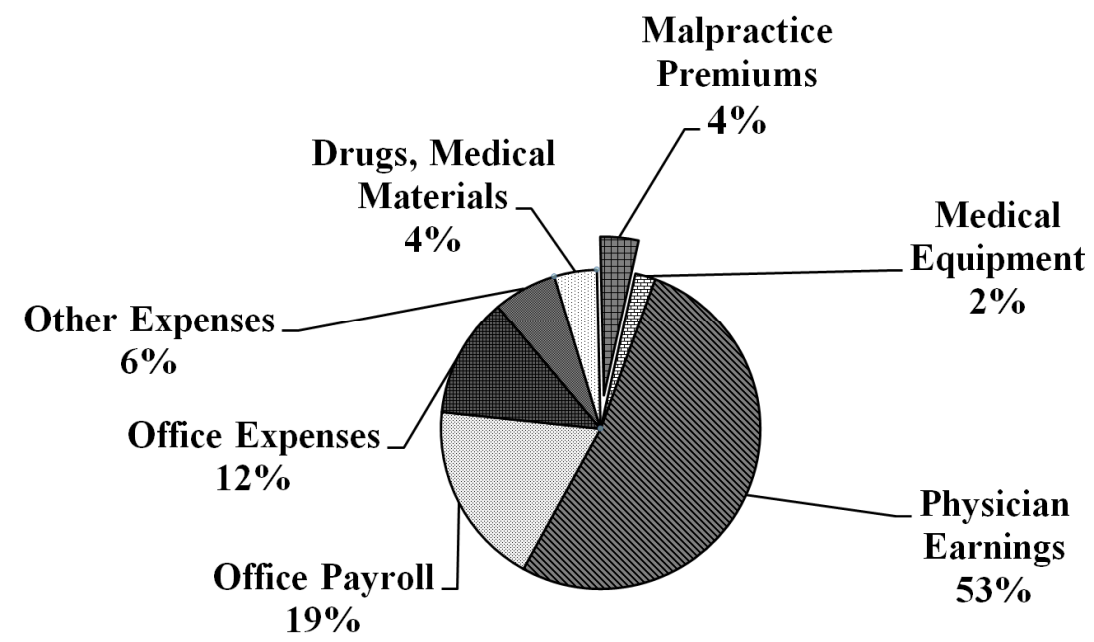

The CMS findings on malpractice premiums were stated as a percentage of gross practice revenue. Total practice costs were 47 percent of gross revenue. Therefore, CMS found that malpractice premiums accounted for about 8 percent of total practice costs as is indicated by the pie-chart below in Figure 10(b).

Figure 10(b). Malpractice premiums as a percentage of total practice expenses for physicians nationally, $2004 .{ }^{118}$

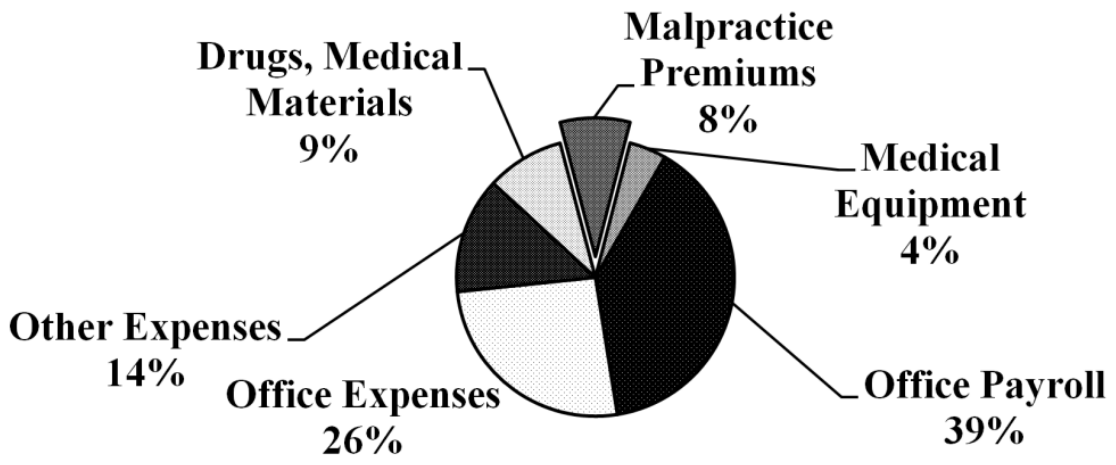

117. Medicare Program, 68 Fed. Reg. at 63,240. Chart compiled by the authors.

118. Id. 
Finally, claims that malpractice premiums make it difficult for physicians to have a viable medical practice need to be evaluated in terms of what is known about physician income in relation to the earnings of other workers in the United States. Physicians remain among the highest-paid professional groups in the country. Mean physician net income in 2003 was between the ninety-fifth and ninetyninth percentiles for all Americans. ${ }^{119}$ As Figure 11 shows, in 2000, physicians had dramatically higher earnings than not only most workers but also most professionals, people with doctorates or masters degrees. ${ }^{120}$

Figure 11. Mean physician income relative to mean income for all full-time year round workers and people with professional degrees, doctorates, and master's degrees in 2000 .

\begin{tabular}{|c|c|c|c|c|c|}
\hline & $\begin{array}{c}\text { Full Time } \\
\text { Workers }\end{array}$ & Physicians & $\begin{array}{c}\text { Professional } \\
\text { Degrees }\end{array}$ & Ph.D. & $\begin{array}{c}\text { Master's } \\
\text { Degrees }\end{array}$ \\
\hline $\begin{array}{c}\text { All } \\
\text { Physicians }\end{array}$ & & $\$ 260,287$ & & & \\
\hline Men & $\$ 59,884$ & & $\$ 135,501$ & $\$ 104,039$ & $\$ 88,123$ \\
\hline Women & $\$ 39,701$ & & $\$ 69,126$ & $\$ 60,523$ & $\$ 51,705$ \\
\hline
\end{tabular}

Sources: Full Time Worker Income from U.S. Census Bureau, Table P-37 Full-Time Year-Round All Workers by Mean Income and Sex: 1955-2013; ${ }^{121}$ Physician income from AMA Surveys; Professional Degree, Doctorate, and Master's Degree income from U.S. Census Bureau, Table P-18 Educational Attainment-People 25 years Old and Over by Mean Income and Sex: 19912013.

Note: Data adjusted by the CPI and expressed in constant 2005 dollars.

119. See David Cay Johnston, Richest Are Leaving Even the Rich far Behind, N.Y. TIMES, June 5, 2005, http://www.nytimes.com/2005/06/05/national/class/HYPERFINAL.html?pagewanted=all\&_r=1\& (citing chart titled "The Wealthiest Benefit More from Tax Cuts").

120. AMA data on physicians do not provide separate income data for women and men physicians. The Census data on earnings used above provide separate income data for women and men and no average for all individuals in these categories.

121. Figures for all other occupations are derived from Historical Income Tables: People, U.S. CEnsus Bureau, http://www.census.gov/hhes/www/income/data/historical/people/ (last updated Sept. 16, 2014). 
To paraphrase Mark Twain's well-known response to finding his obituary prematurely published in a newspaper: The reported recent demise of medical practice as a result of rising malpractice premiums has been greatly exaggerated.

\section{Do Some States Have a Premium Crisis?}

Some states have enacted legislation capping the amount of damage awards. Consequently, premiums in these states might be lower than those without caps. Thus despite offering compelling evidence against claims of a premium crisis on a national and regional basis, the AMA surveys may not be able to reveal a crisis for particular states if these crises occur in states without caps on awards. Several states place caps on the total award; however, most states that do cap awards typically limit payment for pain and suffering or punitive damages, rather than for loss of income or out-of-pocket expenses. As of October 2005, eleven states had laws capping damage awards for non-economic damages at $\$ 250,000$; ten states had legislation that capped awards at between $\$ 250,001$ and $\$ 499,999$; thirteen states had legislation limiting non-economic damages at $\$ 500,000$ or higher; and eighteen jurisdictions did not have any limits on damage awards. ${ }^{122}$

Some studies suggest, however, that the difference in premiums between states with award caps and those without them is slight. In 2003, the Government Accountability Office reviewed studies on the effect of statutory caps on premiums. The GAO concluded that there is disagreement as to whether caps on damages lead to lower premiums and that "a lack of comprehensive data on losses at the

122. States that capped damage awards for non-economic damages: At $\$ 250,000$ (AL, AR, CA, CO, ID, IN, KS, ME, MT, NC, TX); caps between $\$ 250,001$ and $\$ 499,999$ (AK, GA, HI, MI, MO, NV, NJ, OK, SC, UT); caps at $\$ 500,000$ or higher (FL, IL, LA, MD, MA, MS, NE, $\mathrm{NM}, \mathrm{ND}, \mathrm{OH}, \mathrm{SD}, \mathrm{VA}, \mathrm{WV})$; jurisdictions without caps (AL, AZ, CT, DE, IA, KY, MN, NH, NY, OR, PA, RI, TN, VT, WA, WI, WY and Washington, D.C.). See Liability: Limits on Damage Awards, AM. ACAD. OF FAMILY PHYSICIANS (Oct. 2005), available at http://www.aafp.org/dam/AAFP/documents/advocacy/legal/liability/ ES-LiabilityDamage-1005.pdf. See also Medical Liability/Medical Malpractice Laws, NAT'L CONF. ON ST. LEGISLATURES, http://www.ncsl.org/research/financial-services-and-commerce/medicalliability-medical-malpractice-laws.aspx (last updated Aug. 15, 2011). Fourteen jurisdictions do not have a damage award limit or cap, thirtyeight jurisdictions have a limit or cap. Connecticut and Minnesota allow for a court to review of the damage awarded, but does not specify a specific limit or cap. 
insurance company level makes measuring the precise impact of [state caps] impossible." 123

In 2004, Kenneth Thorpe studied how award caps affect premiums. He estimated that in the twenty-five states with caps on damage awards, "premium[s] per physician . . . were associated with a 12 percent reduction in premiums" compared to non-cap states. ${ }^{124}$ In other words, averaging premiums in states with caps and premiums in states without caps for yielded a 12 percent difference in premiums among the two groups of states. Even if we accept Thorpe's conclusion and assume that premiums are 6 percent higher in states with caps than the AMA data indicate (because it averages between states with and without caps), premiums in these states would still be a very small percentage of total practice expenses. They simply would not be large enough to substantially affect net practice income. Using Thorpe's 12 percent finding, for example, premiums still constituted only 2 percent of total practice expenses in 2000. If the reported mean dollar values for premiums for physicians nationally are increased by 6 percent with other expenses and revenue remaining constant, premiums would be 8 percent of total expenses, net income reduced by $\$ 1,252$.

The Thorpe study, however, averaged premiums across twentyfive states with caps on awards. This may hide premium differences among the individual states averaged, still allowing for the possibility of state-specific crises.

A recent study led by David Hyman on the effect of caps on noneconomic damages in Texas found that the effect of caps is less than supposed because damage awards often are reduced to the lower limits of individual liability insurance coverage. ${ }^{125}$ Expressed in 1988 dollars, the cap in Texas reduced the mean payout in cases with jury verdicts by $\$ 184,000$, from $\$ 696,000$ to $\$ 512,000 .{ }^{126}$ Predicted payouts in settled cases declined by $\$ 56,000$, from $\$ 313,000$ to $\$ 257,000$. $^{127}$

Nonetheless, the only way to be certain that no state specific premium crises exist is to obtain reliable data from every state. Although no such data exists, there is a worthy alternative: Reliable data from a state that by all accounts should have a premium crisis if such a crisis exists.

123. GAO REPORT, supra note 51 , at 42 .

124. Thorpe, supra note 96, at W 4-26-27.

125. David A. Hyman, et al., Estimating the Effect of Damages Caps in Medical Malpractice Cases: Evidence From Texas, 1 J. LEGAL ANALYSIS 356, 400 (2009).

126. Id.

127. Id. 


\section{A. Massachusetts as a Test Case}

Based on all available information, if there are states with a premium crisis, Massachusetts should be among them. The AMA itself declared Massachusetts a "crisis state."128 Why? Because Massachusetts has a soft $\$ 500,000$ settlement cap that allows broad exceptions and that is "woefully inadequate," according to the Massachusetts Medical Society, another organization claiming a national premium crisis. $^{129}$

"The AMA is disheartened that the medical liability environment in Massachusetts has deteriorated to the point where physicians are restricting services, and patients are losing access to care," said the AMA's Palmisano in 2004. ${ }^{130}$ The situation outside of Boston is particularly worrisome." 131 Added Alan Woodward, then president of the Massachusetts Medical Society: "Our patients have world-class physicians and health care institutions, but this crisis has been steadily eroding the quality of our health care system for many years." 132

Stoking the panic are data from the National Practitioner Data Bank (NPDB). These data indicate that, from 2000 to 2005, Massachusetts should have had higher premiums than most states because of its high malpractice settlement payments. Malpractice premiums reflect the size of malpractice awards and their frequency. The Massachusetts median settlement payment of $\$ 187,000$ ranked fourth, and its mean settlement payment of $\$ 329,000$ ranked sixth for all jurisdictions nationally. ${ }^{133}$ At 4.34 payments per 100,000 people, the state is ranked 24th in the frequency of awards nationally, but

128. Mass. Med. Soc., Adding Value, Making A Difference - 2004 ANNUAL REPORT 6-7 (2004) http://www.massmed.org/about/mms-2004annual-report-(pdf).

129. Mass. Gen. LaWs ch. 231, § 60H (2000); Mass. Med. Soc'y, Background: Massachusetts Medical Liability Crisis (June 14, 2004) (on file with the author).

130. Massachusetts Becomes 20th State in a Medical Liability Crisis, PR NEWSWIRE (June 14, 2004), http://www.prnewswire.com/newsreleases/massachusetts-becomes-20th-state-in-a-medical-liability-crisis74960777.html.

131. Id.

132. Id

133. U.S. Dept of Health \& human Servs., Health Res. \& Servs. Admin., National Practioner Data Bank - 2005 Annual Report 72 (2005) http://www.npdb.hrsa.gov/resources/reports/2005NPDBAnnualReport. pdf. 
had less than one fewer payment per 100,000 than the ninth highest state. ${ }^{134}$

Only Washington D.C. and Connecticut had both higher mean payment sizes and frequency. Since Massachusetts malpractice payments were among the highest nationally, its premiums should also be high compared to other states. Not the case. In Massachusetts, mean premiums were lower in 2005 than in 1990 for nearly all physicians.

\section{B. The Massachusetts Study Data}

Our study of Massachusetts premiums (the Massachusetts Study) used data from the state regulated mutual insurer, the Medical Professional Mutual Insurance Company, known as ProMutual Group (PMG), which since 1975, has been the state's main medical malpractice insurer. ${ }^{135}$ Its insurance rates reflect prices available to most physicians.

In 1975, as a result of the exit of commercial malpractice insurers from Massachusetts, the legislature created the Massachusetts Medical Malpractice Joint Underwriting Association (MMJUA). The legislature converted it into the Massachusetts Medical Professional Insurance Association in 1993 and then in 1995 to ProMutual. Around the time of the formation of the MMJUA, Harvard affiliated hospitals created the Controlled Risk Insurance Company (CRICO) for its affiliated physicians.

Since their creation in the late 1970s, the MMJUA/ProMutual and CRICO controlled about 90 percent of the physicians' liability insurance market, each covering about half that market. ${ }^{136}$ In 2005 , A.M. Best (a U.S.-based rating agency focused on the insurance industry) reported that the ProMutual Group covered 77 percent of regulated professional liability insurance, which includes other medical professionals and health care institutions. Those physicians that did not purchase insurance from the ProMutual Group or CRICO purchased insurance from other state regulated insurers or from unregulated risk-retention groups and offshore insurers.

134. Id. Calculations based on National Practitioner Data Bank. Data adjusted by state population from U.S. Census data for 2001-2004.

135. The author had restricted access to the raw data used to compile the figures in this section. As a result of this restriction, the Editor was unable to review the raw data before going to print.

136. See Johnston, surpa note 119 (citing the chart "The Wealthiest Benefit More from Recent Tax Cuts"). 


\section{How Insurers Set Premiums}

To understand changes in the cost of professional liability insurance, it helps to consider the various kinds of liability insurance available. Insurers sell several types of policies, each priced differently. Policies vary based on the time period covered and the dollar amount of liability coverage. Insurers set premiums based on three key variables: (1) risk of loss (which can vary with practice specialty and other factors), (2) the dollar amount of protection, and (3) the time period covered. ${ }^{137}$

Insurers calculate each practice specialty's risk of loss and assign it to a premium rate group. ${ }^{138}$ Once insurers assign each practice specialty to a rate group, they can refine their risk assessment based on many other factors including the physician's claims history, length of time in medical practice, their work setting, and organizational affiliation. ${ }^{139}$

Policies specify a maximum amount that can be reimbursed both per claim and yearly for all claims. Massachusetts initially required that physicians purchase at least $\$ 100,000$ of loss coverage per claim with coverage capped at a $\$ 300,000$ yearly loss. ${ }^{140}$ Starting in 1987 , the Massachusetts Board of Registration required physicians to purchase up to $\$ 100,000$ coverage per claim, capped at a $\$ 300,000$ yearly loss. ${ }^{141}$ In $2006, \$ 1 / \$ 3$ million coverage was the most frequently purchased amount of liability protection, and $\$ 2 / \$ 6$ million coverage was the second most frequent level of protection purchased. ${ }^{142}$

Patients often do not file claims in the same year that the incident occurred, though statutes of limitation restrict the time that patients have to file. Professional liability insurance policies cover either periods when alleged negligence occurs, regardless of when

137. SloAn \& ChePKe, supra note 12 , at 5-15, 34-36.

138. ProMutual Group had eight rate groups in 1975. As it obtained more information, PMG refined its risk analysis. It used fifteen rate groups by 1990 and nineteen by 2005 .

139. In 1990, PMG began to selectively discount rates within practicespecialty rate groups based on these and other factors. In 2000, PMG increased the frequency and size of its discounts and occasionally imposed surcharges on physicians it deemed high-risks.

140. 243 Mass. Code Regs. 2.07 (16) (1987).

141. 243 C.M.R. $\S 2.07(16)$.

142. States vary on whether they require physicians to purchase liability insurance, and if so, what amount. However, even if states do not mandate that physicians must purchase a minimum dollar amount of liability insurance, often hospitals require that physicians do as a condition for granting physicians privileges to practice in the hospital. 
claims are filed (occurrence policies), or periods during which patients file negligence claims (claims-made policies).

Physicians renewing a claims-made policy are covered from the first year that they owned the policy. Premiums are higher for claimsmade policies in the second, third, and fourth years because the policies cover a longer time. Insurers also sell mature claims-made policies that cover five or more years of past practice.

Occurrence policies are more expensive than first through fourth year claims-made policies and less than mature claims-made policies. The cost of insurance through claims-made and occurrence policies generally converge over time because physicians who do not renew a claims-made policy need to purchase "tail insurance" for claims filed later.

\section{Grouping Physicians into Five Practice Tiers}

The Massachusetts study focused on $\$ 1 / \$ 3$ million and $\$ 2 / \$ 6$ million occurrence policies because together, these two types accounted for 81.2 percent of the policies in 2005. Occurrence policies are the second most expensive type of policy. Mature claims-made policies, which are slightly more expensive than occurrence policies, comprised 10.7 percent of all policies.

In 2005, 54.6 percent of PMG's policies were for $\$ 1 / \$ 3$ million occurrence and 26.6 percent were for $\$ 2 / \$ 6$ million occurrence. Nearly 66 percent of PMG's occurrence policies were for $\$ 1 / \$ 3$ million coverage, 30.3 percent were for $\$ 2 / \$ 6$ million; only 1.6 percent provided greater coverage. In 2005, 67.4 percent of all $\mathrm{PMG}$ 's policies were for $\$ 1 / \$ 3$ million coverage and 30.3 percent were for $\$ 2 / \$ 6$ million coverage.

While the raw data provided information on each rate group, policy type, and dollar amount of coverage, reviewing the information for nineteen rate groups, six policy durations, and several levels of dollar coverage is much too cumbersome. Further, the data showed only small differences in premiums among the rate groups. To clarify the main trends, the Massachusetts study divided the nineteen rate groups into five tiers. The 2005 practice specialties in each tier and percentage of physicians in each tier are listed below, starting with the most expensive tier and descending to the least expensive tier:

-Tier 1. Four percent of physicians: OB/GYN, neurological surgery, and orthopedists performing spinal surgery.

- Tier 2. Four percent of physicians: Major vascular, cardiovascular, head and neck, traumatic, and orthopedic (except spinal) surgery.

-Tier 3. Five percent of physicians: Major general, abdominal, thoracic, plastic, cardiac and gynecological or hand surgery, and emergency medicine without major surgery. 
-Tier 4. Eight percent of physicians: Anesthesiology and major surgery for emergency medicine, ronco-esophagology, colon and rectal, endocrinology, gastroenterology, geriatrics, neoplastic, nephrology, laryngology, otology, orhinolaryngology, rhinology, and urology.

-Tier 5. Seventy-eight percent of physicians: All other physicians, which includes sixty-five practice specialties.

The Massachusetts study supplied the most detailed data on malpractice premiums available. It reported:

-State regulated insurance manual rates for each practice specialty;

- Rate differences for six types of policies with varying duration of coverage;

- Rate differences based on the maximum dollar amount of liability protection;

-Discounts and surcharges to insurance manual rates that accurately reflect the actual amount that physicians pay;

- The percentage of physicians purchasing policies with various dollar limits on coverage and duration of coverage from 1990 to 2005. This shows changes in what kind of insurance physicians purchase, not just price changes for fixed coverage; and

-Long-term trends and short-term change from 1975 to 2005. ProMutual Group raised rates 5 percent in 2006, while in 2007 it did not increase rates, but instead decreased them for some high-risk specialties.

\section{E. 30-Year Manual Rate Trends for the Five Practice Tiers}

Figure 12 displays as a line graph the $\$ 1 / \$ 3$ million occurrence manual rates from 1975 to 2005. Figure 13 displays the numerical values. These figures indicate the mean tier rates by averaging the rates of each practice specialty group within each tier. This does not account for differences in the number of physicians within different rate groups. That information will be provided later, but it will only include data from 1990 and later because ProMutual Group did not have such data prior to that time. 
Figure 12. Massachusetts mean insurance manual premium rates for $\$ 1 / \$ 3$ million coverage occurrence policies for all physicians and physicians divided into five tiers, adjusted by number of rate groups in each tier; 1975-2005.

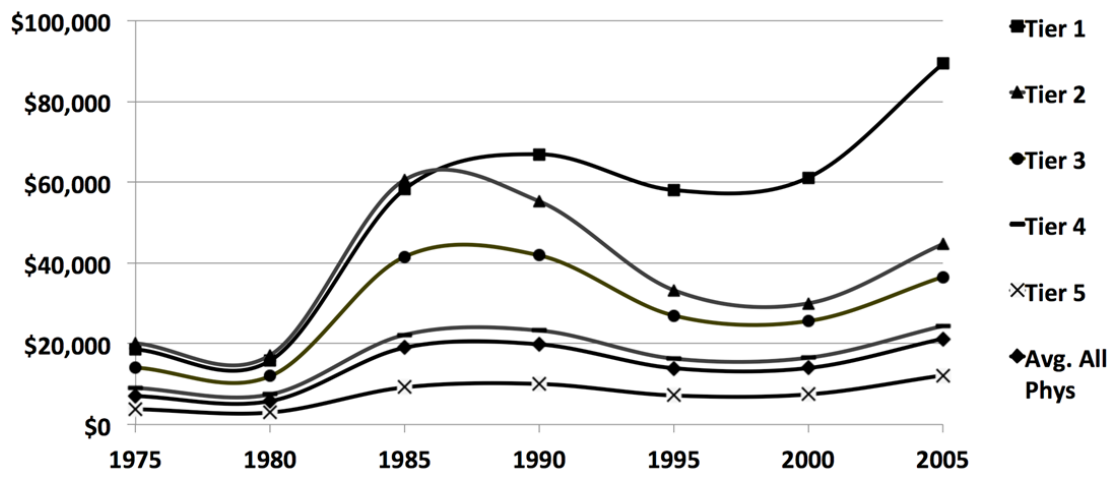

Source: Medical Professional Insurance Co.

Notes: All data adjusted by CPI and expressed in constant 2005 dollar. All percentages of physicians are for 2005. Practice specialties were divided into tiers charged similar rates.

Figure 13. Massachusetts mean manual premium rates for all physicians and physicians divided into five tiers for $\$ 1 / \$ 3$ million coverage occurrence policies unadjusted by count, 1975-2005.

\begin{tabular}{|c|r|r|r|r|r|r|r|}
\hline & $\mathbf{1 9 7 5}$ & $\mathbf{1 9 8 0}$ & $\mathbf{1 9 8 5}$ & $\mathbf{1 9 9 0}$ & $\mathbf{1 9 9 5}$ & $\mathbf{2 0 0 0}$ & $\mathbf{2 0 0 5}$ \\
\hline Tier 5 & $\$ 3,870$ & $\$ 2,990$ & $\$ 9,215$ & $\$ 10,056$ & $\$ 7,202$ & $\$ 7,472$ & $\$ 12,165$ \\
\hline Tier 4 & $\$ 8,978$ & $\$ 7,460$ & $\$ 22,211$ & $\$ 23,276$ & $\$ 16,325$ & $\$ 16,538$ & $\$ 24,417$ \\
\hline Tier 3 & $\$ 14,152$ & $\$ 11,984$ & $\$ 41,561$ & $\$ 41,883$ & $\$ 26,998$ & $\$ 25,625$ & $\$ 36,557$ \\
\hline Tier 2 & $\$ 20,098$ & $\$ 17,184$ & $\$ 60,594$ & $\$ 55,269$ & $\$ 33,271$ & $\$ 30,013$ & $\$ 44,686$ \\
\hline Tier 1 & $\$ 18,547$ & $\$ 15,827$ & $\$ 58,263$ & $\$ 66,927$ & $\$ 58,055$ & $\$ 61,148$ & $\$ 89,319$ \\
\hline $\begin{array}{c}\text { 5 Tier } \\
\text { Average }\end{array}$ & $\mathbf{\$ 7 , 0 9 5}$ & $\mathbf{\$ 5 , 8 1 1}$ & $\mathbf{\$ 1 9 , 0 2 8}$ & $\mathbf{\$ 1 9 , 8 5 5}$ & $\mathbf{\$ 1 3 , 9 5 5}$ & $\mathbf{\$ 1 3 , 9 8 7}$ & $\mathbf{\$ 2 1 , 2 4 5}$ \\
\hline
\end{tabular}

According to the data, mean insurance manual rates for all physicians grew only slightly over 30 years with rise and fall cycles. Mean rates increased from $\$ 7,095$ in 1975 , then declined to $\$ 5,811$ in 1980 and then rose again to $\$ 19,855$ in 1990 . Rates then declined to $\$ 13,955$ in 1995 before rising to $\$ 21,245$ in 2005 . The five tiers showed similar trends with the exception of Tier 1, which included practice specialties with the highest risk of liability and premiums.

Tier 5, which included 78 percent of physicians in 2005, experienced smaller rises and declines in the premium cycle than the mean for all physicians. Tier 5 rates rose from $\$ 3,870$ in 1975 to their 
30 -year high of $\$ 12,165$ in 2005 . Tier 5 rates were $\$ 10,056$ in 1990, its second highest year, up from $\$ 2,990$ in 1980 , its lowest year. Tier 4 rates stayed only slightly higher than the mean for all physicians.

Tiers 1 through 3 rates were much higher than for most physicians, especially in their peak years. Tier 3 and 2 rates soared from 1980 to 1990, declined until 1995 or 2000 and increased thereafter. In 2005, however, they were lower than in 1990. Between 1990 and 2005, Tier 2 and Tier 3 rates declined by more than $\$ 10,583$ and $\$ 5,326$, respectively.

Only Tier 1 rates ended much higher in 2005 than in 1990. Although they declined from 1990 to 1995, between 1990 and 2005 the mean rate increased by $\$ 22,392$ to $\$ 89,319$.

These data reveal that something atypical is occurring for premiums of physicians practicing obstetrics, neurological, and spinal surgery. Their premiums are much higher than all other practice specialties. If there is any crisis in premiums, then it is for these practice specialties, which represent only 4 percent of practicing physicians. The data indicate that these practice specialties have atypically high premiums.

The key reason that premiums are higher for these practice specialties is that the kind of injuries occurring due to negligence can be much more harmful than in other areas. Although giving birth is relatively routine and safe for most women and their children, a small percentage of infants may be deprived of oxygen during birth, for example, and suffer catastrophic injuries. This can result in the infant surviving, but also requiring custodial care for the remainder of his or her life. Similarly, neurological surgery involving the spine may result in injuries leading to paralysis if the surgery goes awry. This too could require life-long care.

\section{F. Distribution of Physicians by Dollar Amount of Insurance Manual Rates 1990 to 2005}

Another way to analyze the price of liability insurance is to report the percentage of physicians charged different rates, separated by $\$ 10,000$ increments. PMG began keeping this data in 1990. Figure 14 shows the distribution of physicians charged different manual rates per $\$ 10,000$ increments from 1990 to 2005 .

Between 1990 and 2005, physicians with rates under $\$ 20,000$ increased from 72 percent to 78 percent. Within this group, physicians moved into higher premium levels. Physicians with high premiumsmore than $\$ 60,000$ - decreased from 8 percent to 4 percent. Physicians with premiums above $\$ 70,000$ increased from zero to 4 percent. Those in the middle range $\$ 20,000$ to $\$ 60,000$ - decreased from 20 percent to 17 percent. Within the group as a whole, physicians moved to the middle. In 2005, 29 percent of physicians with $\$ 1 / \$ 3$ million 
occurrence coverage had premiums under $\$ 10,000 ; 78$ percent had premiums under $\$ 20,000$; and 92 percent had premiums under $\$ 40,000$. Only 4 percent of physicians had premiums above $\$ 50,000$.

In 2005,23 percent of physicians with $\$ 2 / \$ 6$ million coverage had rates under $\$ 10,000 ; 63$ percent had rates under $\$ 20,000$, and 95 percent had rates under $\$ 40,000$. Only 5 percent of physicians received rates above $\$ 40,000$, only 1 percent more than $\$ 60,000$. From 1990 to 2005, the highest rate group shrank while the lowest rate group expanded.

Figure 14. Distribution of physicians by dollar amount of manual premium rates, prior to discounts and surcharges, for occurrence policies of $\$ 1 / \$ 3$ million and $\$ 2 / \$ 6$ million coverage, 1990-2005.

\begin{tabular}{|c|c|c|c|c|}
\hline \multicolumn{5}{|c|}{ \$1/\$3 Million Occurrence Policies } \\
\hline & 1990 & 1995 & 2000 & 2005 \\
\hline \multicolumn{5}{|l|}{ Under 10K } \\
\hline \multicolumn{5}{|l|}{$10 \mathrm{~K}$ to $20 \mathrm{~K}$} \\
\hline \multicolumn{5}{|l|}{$20 \mathrm{~K}$ to $30 \mathrm{~K}$} \\
\hline $30 \mathrm{~K}$ to $40 \mathrm{~K}$ & $2 \%$ & $4 \%$ & $3 \%$ & $5 \%$ \\
\hline $40 \mathrm{~K}$ to $50 \mathrm{~K}$ & $2 \%$ & $1 \%$ & 1\% & $4 \%$ \\
\hline & & & & \\
\hline $50 \mathrm{~K}$ to $60 \mathrm{~K}$ & $2 \%$ & $4 \%$ & $4 \%$ & $0 \%$ \\
\hline $60 \mathrm{~K}$ to $70 \mathrm{~K}$ & $8 \%$ & $0 \%$ & $0 \%$ & $0 \%$ \\
\hline & & & & \\
\hline Over 70K & $0 \%$ & $0 \%$ & $0 \%$ & $4 \%$ \\
\hline Count & 5,632 & 9,438 & 7,179 & 5,678 \\
\hline \multicolumn{5}{|c|}{ \$2/\$6 Million Occurrence Policies } \\
\hline \multirow{2}{*}{ Under 10K } & 1990 & 1995 & 2000 & 2005 \\
\hline & $17 \%$ & $56 \%$ & $39 \%$ & $23 \%$ \\
\hline $10 \mathrm{~K}$ to $20 \mathrm{~K}$ & $62 \%$ & $33 \%$ & $46 \%$ & $40 \%$ \\
\hline $20 \mathrm{~K}$ to $30 \mathrm{~K}$ & $9 \%$ & $5 \%$ & $8 \%$ & $20 \%$ \\
\hline $30 \mathrm{~K}$ to $40 \mathrm{~K}$ & $3 \%$ & $0.80 \%$ & $2 \%$ & $12 \%$ \\
\hline $40 \mathrm{~K}$ to $50 \mathrm{~K}$ & $0 \%$ & $0.60 \%$ & $2 \%$ & $2 \%$ \\
\hline $50 \mathrm{~K}$ to $60 \mathrm{~K}$ & $2 \%$ & $0.60 \%$ & $0 \%$ & $2 \%$ \\
\hline \multirow[t]{2}{*}{$60 \mathrm{~K}$ to $70 \mathrm{~K}$} & $0 \%$ & $0.09 \%$ & $0 \%$ & $0 \%$ \\
\hline & & & & \\
\hline Over 70K & $7 \%$ & $4 \%$ & $3 \%$ & $1 \%$ \\
\hline Count & 670 & 1,067 & 2,209 & 2,358 \\
\hline
\end{tabular}


G. Adjusting Mean Manual Rates for the Number of Physicians in Each Rate Group

The previous statistics for the five tiers were computed by averaging the rates of each group. Some rate groups, however, have many more physicians than others. A more accurate measure of central tendency would take account of this by weighing the average with the number of physicians in each rate group. Figure 15 displays mean premiums since 1990 for each tier weighed by the number of physicians in each rate group. Again, PMG only has data on the number of physicians in each rate group since 1990.

Figure 15. Mean manual premiums for five physician tiers weighted by the number of physicians in each rate group for $\$ 1 / \$ 3$ million and $\$ 2 / \$ 6$ million occurrence policies, 1990-2005 including percentage of physicians in each tier, 1990-2005.

\begin{tabular}{|c|c|c|c|c|}
\hline \multicolumn{5}{|c|}{ \$1/ \$3 Million Occurrence Policies } \\
\hline & 1990 & 1995 & 2000 & 2005 \\
\hline \multirow[t]{2}{*}{ Tier 5} & $\$ 9,119$ & $\$ 7,098$ & $\$ 7,281$ & $\$ 10,375$ \\
\hline & $72 \%$ & $78 \%$ & $79 \%$ & $78 \%$ \\
\hline \multirow[t]{2}{*}{ Tier 4} & $\$ 23,875$ & $\$ 15,988$ & $\$ 16,331$ & $\$ 24,916$ \\
\hline & $14 \%$ & $8 \%$ & $7 \%$ & $8 \%$ \\
\hline \multirow[t]{2}{*}{ Tier 3} & $\$ 41,932$ & $\$ 27,039$ & $\$ 25,376$ & $\$ 36,557$ \\
\hline & $4 \%$ & $5 \%$ & $5 \%$ & $5 \%$ \\
\hline \multirow[t]{2}{*}{ Tier 2} & $\$ 51,815$ & $\$ 37,024$ & $\$ 32,856$ & $\$ 44,289$ \\
\hline & $2 \%$ & $4 \%$ & $5 \%$ & $4 \%$ \\
\hline \multirow[t]{2}{*}{ Tier 1} & $\$ 66,220$ & $\$ 60,981$ & $\$ 65,612$ & $\$ 95,045$ \\
\hline & $8 \%$ & $5 \%$ & $4 \%$ & $4 \%$ \\
\hline $\begin{array}{l}5 \text { Tier } \\
\text { Mean }\end{array}$ & $\$ 17,907$ & $\$ 12,891$ & $\$ 12,551$ & $\$ 17,810$ \\
\hline $\begin{array}{c}\text { No. of } \\
\text { Doctors }\end{array}$ & 5,632 & 9,438 & 7,179 & 5,678 \\
\hline \multicolumn{5}{|c|}{ \$2/ \$6 Million Occurrence Policies } \\
\hline & 1990 & 1995 & 2000 & 2005 \\
\hline \multirow[t]{2}{*}{ Tier 5} & $\$ 13,446$ & $\$ 8,812$ & $\$ 10,214$ & $\$ 14,658$ \\
\hline & $83 \%$ & $90 \%$ & $84 \%$ & $84 \%$ \\
\hline \multirow[t]{2}{*}{ Tier 4} & $\$ 31,127$ & $\$ 21,104$ & $\$ 22,601$ & $\$ 30,153$ \\
\hline & $8 \%$ & $4 \%$ & $8 \%$ & $12 \%$ \\
\hline \multirow[t]{2}{*}{ Tier 3} & $\$ 62,464$ & $\$ 38,569$ & $\$ 35,961$ & $\$ 45,422$ \\
\hline & $3 \%$ & $1 \%$ & $2 \%$ & $2 \%$ \\
\hline \multirow[t]{2}{*}{ Tier 2} & $\$ 71,225$ & $\$ 52,160$ & $\$ 46,511$ & $\$ 55,003$ \\
\hline & $0 \%$ & $1 \%$ & $2 \%$ & $2 \%$ \\
\hline \multirow[t]{2}{*}{ Tier 1} & $\$ 94,307$ & $\$ 83,236$ & $\$ 95,867$ & $\$ 117,541$ \\
\hline & $5 \%$ & $4 \%$ & $3 \%$ & $1 \%$ \\
\hline $\begin{array}{l}5 \text { Tier } \\
\text { Mean }\end{array}$ & $\$ 20,872$ & $\$ 13,115$ & $\$ 15,067$ & $\$ 18,722$ \\
\hline $\begin{array}{c}\text { No. of } \\
\text { Doctors }\end{array}$ & 670 & 1,067 & 2,209 & 2,358 \\
\hline
\end{tabular}


Source: Medical Professional Mutual Insurance Co.

Note: All data adjusted by CPI and expressed in constant 2005 dollars. Practice specialties divided into tiers charged similar rates.

Between 1990 and 2005, mean premiums for all physicians purchasing $\$ 1 / \$ 3$ million occurrence policies decreased from $\$ 17,907$ to $\$ 17,810$. As noted previously, mean premiums for physicians collectively were not at an all-time high in 2005 - the peak year was 1990. Premiums fell thereafter until 2000 before rising again to the amount charged in 2005.

Mean premiums in Tiers 5 and 4 also cycled down and up and ultimately rose just over $\$ 1,250$ and $\$ 1,040$, respectively, from 1990 to 2005. Rates for Tiers 1 through 3 were much higher than for most physicians, especially at their peaks. Tier 2 and Tier 3 rates declined until 1995 or 2000 and increased thereafter. Still, in 2005, those rates were lower than in 1990. Tier 2 and Tier 3 premiums declined by more than $\$ 5,375$ and $\$ 7,526$, respectively, between 1990 and 2005 and ended at $\$ 44,289$ and $\$ 36,557$. Only Tier 1 premiums were much higher in 2005 than in 1990 . Tier 1 premiums increased from $\$ 28,825$ in 1990 to $\$ 95,045$ in 2005 . Trends are similar for $\$ 2 / \$ 6$ million coverage, with the exception of Tier 4 premiums which decreased from 1990 to 2005.

To summarize, these data support the previous findings: Premium rates for most physicians were not high and, in fact, declined from 1990 to 2005. However, physicians practicing obstetrics, neurological, or spinal surgery are the exception; they paid much higher premiums than all other physicians and their mean rates increased from 1990 to 2005 .

\section{H. Relation of Reported Premiums to Premiums of Other Policies}

How do the premiums for the $\$ 1 / \$ 3$ million and $\$ 2 / \$ 6$ million occurrence policies just analyzed differ from the premiums of other policies?

Figure 16 shows 2005 premiums for PMG's 19 rate groups under $\$ 1 / \$ 3$ million coverage and the percentage of physicians purchasing such policies from 1990 to 2005. Occurrence policies in 2005 cost $\$ 3,473$ more than first-year claims-made coverage for rate group 1 and $\$ 65,740$ more for rate group 19. Comparing mature claims-made premiums to occurrence policies, the former were $\$ 375$ more than in rate group 1 and $\$ 7,763$ more in rate group 19 . 
Figure 16. 2005 manual premium rates in dollars for first-year claims-mademature claims-made policies and occurrence policies for $\$ 1 / \$ 3$ million coverage. percentage distribution of physicians purchasing occurrence policies by rate group, 1990-2005.

\begin{tabular}{|c|c|c|c|c|c|c|c|c|c|c|}
\hline \multirow[t]{2}{*}{$\begin{array}{l}\text { Rate } \\
\text { Group }\end{array}$} & \multirow[t]{2}{*}{$\begin{array}{l}\text { 1st } \\
\text { Year } \\
\text { Claims } \\
\text { Made }\end{array}$} & \multirow[t]{2}{*}{$\begin{array}{l}\text { 2nd } \\
\text { Year } \\
\text { Claims } \\
\text { Made }\end{array}$} & \multirow[t]{2}{*}{$\begin{array}{l}\text { 3rd Year } \\
\text { Claims } \\
\text { Made }\end{array}$} & \multirow[t]{2}{*}{$\begin{array}{l}\text { 4th Year } \\
\text { Claims } \\
\text { Made }\end{array}$} & \multirow[t]{2}{*}{$\begin{array}{l}\text { Mature } \\
\text { Claims } \\
\text { Made }\end{array}$} & \multirow[t]{2}{*}{$\begin{array}{l}\text { Occur- } \\
\text { rence }\end{array}$} & \multicolumn{4}{|c|}{$\begin{array}{l}\text { Percentage Distribution of Physicians } \\
\text { Purchasing Occurrence Policies by } \\
\text { Rate Group 1990-2005 }\end{array}$} \\
\hline & & & & & & & 1990 & 1995 & 2000 & 2005 \\
\hline 1 & 1,650 & 2,749 & 4,125 & 4,950 & 5,498 & 5,123 & $7.0 \%$ & $9.5 \%$ & $11.9 \%$ & $14.2 \%$ \\
\hline 2 & 2,092 & 3,485 & 5,229 & 6,274 & 6,970 & 6,493 & $4.1 \%$ & $14.3 \%$ & $14.4 \%$ & $14.7 \%$ \\
\hline 3 & 3,559 & 5,930 & 8,897 & 10,675 & 11,863 & 11,050 & $44.7 \%$ & $10.7 \%$ & $10.8 \%$ & $12.7 \%$ \\
\hline 4 & 3,873 & 6,454 & 9,682 & 11,616 & 12,908 & 12,023 & $9.9 \%$ & $22.6 \%$ & $21.3 \%$ & $21.8 \%$ \\
\hline 5 & 4,021 & 6,704 & 10,055 & 12,064 & 13,405 & 12,413 & $2.1 \%$ & $1.7 \%$ & $1.7 \%$ & $1.4 \%$ \\
\hline 6 & 4,528 & 7,546 & 11,318 & 13,580 & 15,089 & 14,055 & $1.8 \%$ & $2.4 \%$ & $2.6 \%$ & $2.3 \%$ \\
\hline 7 & 5,068 & 8,447 & 12,674 & 15,208 & 16,897 & 15,739 & $2.2 \%$ & $5.8 \%$ & $5.6 \%$ & $4.7 \%$ \\
\hline 8 & 5,613 & 9,356 & 14,033 & 16,838 & 18,709 & 17,327 & $6.3 \%$ & $4.9 \%$ & $5.3 \%$ & $3.4 \%$ \\
\hline 9 & 5,881 & 9,803 & 14,706 & 17,646 & 19,607 & 18,266 & $0.1 \%$ & $3.0 \%$ & $1.9 \%$ & $0.5 \%$ \\
\hline 10 & 6,111 & 10,184 & 15,277 & 18,332 & 20,370 & 18,974 & $8.0 \%$ & $2.8 \%$ & $3.1 \%$ & $2.6 \%$ \\
\hline 11 & 7,716 & 12,862 & 19,293 & 23,151 & 25,724 & 23,822 & $2.2 \%$ & $0.1 \%$ & $0.0 \%$ & $0.2 \%$ \\
\hline 12 & 7,880 & 13,135 & 19,701 & 23,641 & 26,268 & 24,327 & $1.7 \%$ & $2.3 \%$ & $2.5 \%$ & $2.5 \%$ \\
\hline 13 & 8,131 & 13,553 & 20,331 & 24,396 & 27,108 & 25,251 & $1.6 \%$ & $5.5 \%$ & $4.9 \%$ & $5.2 \%$ \\
\hline 14 & 11,842 & 19,737 & 29,606 & 35,527 & 39,474 & 36,557 & $2.8 \%$ & $4.9 \%$ & $5.0 \%$ & $5.4 \%$ \\
\hline 15 & 14,270 & 23,781 & 35,672 & 42,807 & 47,563 & 44,046 & $5.6 \%$ & $2.6 \%$ & $3.1 \%$ & $3.0 \%$ \\
\hline 16 & 14,527 & 24,212 & 36,320 & 43,582 & 48,425 & 44,846 & & $1.4 \%$ & $1.6 \%$ & $1.3 \%$ \\
\hline 17 & 23,350 & 38,918 & 58,377 & 70,054 & 77,836 & 72,080 & & $0.6 \%$ & $0.5 \%$ & $0.2 \%$ \\
\hline 18 & 29,386 & 48,975 & 73,463 & 88,156 & 97,951 & 90,710 & & $0.5 \%$ & $0.4 \%$ & $0.6 \%$ \\
\hline 19 & 31,503 & 52,502 & 78,754 & 94,506 & 105,006 & 97,243 & & $4.4 \%$ & $3.4 \%$ & $3.2 \%$ \\
\hline \multicolumn{7}{|c|}{ Total Number of Physicians } & 5,632 & 9,438 & 7,179 & 5,678 \\
\hline
\end{tabular}

Source: Medical Professional Mutual Insurance Co.

Note: All data adjusted by CPI and expressed in constant 2005 dollars.

\section{How Manual Rate Discounts and Surcharges Affect the Premiums Physicians Pay}

After 1990, insurance manual rates became a less reliable measure of the amounts that physicians paid for insurance because PMG began to discount or surcharge rates. Initially, PMG discounted premiums for only some physicians. Around 2000 it increased the size and frequency of these discounts and started to impose rate surcharges for some high-risk physicians - nearly all physicians who were not high-risk received some discount, frequently around 5 percent, but some received much larger discounts than others. By 2000, however, PMG began increasing discount frequency and size as well as surcharging physicians. 
In 2005, PMG discounted 88.7 percent of policies. ${ }^{143}$ Sixty-five percent of physicians received discounts between zero and 25 percent while 23.6 percent received discounts between 25 percent and 50 percent. PMG also surcharged rates for 6 percent of physicians. Fourand-a-half percent of physicians paid surcharges under 25 percent and 1.4 percent paid surcharges above 25 percent. Adjusting the Tier 1 premiums for discounts and surcharges, physicians paying more than $\$ 70,000$ fell from 4 percent to 2.7 percent; 1.1 percent paid $\$ 60,000$ to 70,000 , and 0.1 percent paid $\$ 50,000$ to $\$ 60,000$.

In $2005,66.7$ percent of all $\$ 1 / \$ 3$ million occurrence policies were discounted by more than 12 percent. Reducing 2005 rates by just over 12 percent for Tier 5 , and by only 5 percent for Tier 4, resulted in lower premiums than in 1990. Consequently, premiums for most physicians in Tiers 4 and 5 were lower in 2005 than in 1990. Mean rates for Tiers 2 and 3 were lower in 2005 than in 1990 even before adjusting for discounts and surcharges. Tier 1, however, continued to be the exception, having a higher mean premium in 2005 than in 1990 even after adjusting for its mean discount of $\$ 11,014$.

As the above analysis makes clear, after adjusting for discounts, nearly all physicians in Tiers 2, 3, and 4 paid lower premiums in 2005 than they did in 1990. So, if premiums were actually a burden on practice income, they were a greater problem in 1990 than at any point between 1990 and 2005.

But what about Tier 1 physicians? Could they have experienced a premium crisis?

143. PMG discounted rates in 2005 as follows:

- Interns, residents, and fellows working in a facility insured by PMG: $25 \%$ or $15 \%$;

- Physicians in first and second year practice: $50 \%$ and $25 \%$;

- Physicians in academic settings or community service treating patients 21 hours a week or less: $50 \%$;

- $\quad$ Emergency medicine physicians: up to $20 \%$;

- Physicians covered by the Federal Tort Claims Act: between $25 \%$ and $50 \%$; and

- $\quad$ PMG reduced premiums additionally up to $25 \%$ for physicians deemed low-risk and surcharged physicians deemed high-risk up to $25 \%$. Physicians with no closed claims over $\$ 10,000$ received discounts between $3 \%$ and $15 \%$, based on the duration of clean claims. Group practices with a favorable claims history also received discounts. 


\section{J. Obstetrics and Other Tier 1 Practice Specialties}

Figures 17 and 18 reveal premium variations in Tier 1 . Figure 17 displays dollar values for each of the Tier 1 practice specialties' mean and median manual rates, mean premiums adjusted by discounts and surcharges, and the lowest and highest premiums paid in 2000 and 2005. Figure 18 displays the percentage of physicians who received discounts in each of Tier 1's specialties in 2000 and 2005.

According to the data, premiums for Tier 1 physicians with $\$ 1 / \$ 3$ million coverage varied widely in 2005 . The OB/GYN manual rate was $\$ 97,243$, about $\$ 8,700$ more than its 1990 level. Depending on rate-adjustment, however, OB/GYN premiums ranged from $\$ 48,622$ to $\$ 145,865$. Few Tier 1 physicians purchased $\$ 2 / \$ 6$ million coverage in 2005. But nearly all OB/GYNs with $\$ 2 / \$ 6$ million coverage paid the insurance manual rate with more paying surcharges than receiving discounts.

Since 1990, the highest rates were for OB/GYNs. To examine OB/GYN premiums in more detail, the Massachusetts study supplemented OB/GYN occurrence data with claims-made data. Figure 19 displays insurance manual rates, mean premiums adjusted by discounts and surcharges, the lowest and highest premiums paid, and the percentage of physicians who paid these rates for all $\$ 1 / \$ 3$ million occurrence policies in 2000 and 2005. The data for $\$ 2 / \$ 6$ occurrence was not reported since only 20 policies for this coverage were purchased, and that sample size is too small for any meaningful comparison.

In 2000, OB/GYN occurrence rates were $\$ 69,361$, about $\$ 275$ more than 1990 rates. Due to discounts and surcharges, however, 88 percent of OB/GYN's paid less than in 1990. Claims-made premiums reveal similar patterns as mean weighted premiums were lower than in 1990. By 2005, only 3 percent of OB/GYNs with occurrence policies paid the manual rate of $\$ 97,243$ and twenty-nine percent paid less than the 1990 rate. Between 53 percent and 76.2 percent of OB/GYNs purchasing first year through fourth year claims-made policies received discounts, yet most paid more than 1990 rates. Premiums varied greatly: The highest were more than twice the lowest.

In summary, nearly all of the 97 percent of physicians in Tiers 2 through 5 paid lower premiums in 2005 than in 1990. Concerns that premiums are higher now than ever before are clearly unfounded. Only a few selective practice specialties appear to pay higher premiums. Even so, the premiums of the three practice specialties in the highest rate tier reveal great variation in premiums paid-some had substantial premium increases since 1990 while for others, premiums declined. For OB/GYNs, the practice specialty with the highest premiums, the most costly year for all physicians was not 
2005. During that year, nearly a third of those physicians paid less than they did in 1990 .

Figure 17. Top three practice specialty manual premium rates and mean, median, low, and high premiums adjusted for discounts and surcharges for $\$ 1 / \$ 3$ million and $\$ 2 / \$ 6$ million occurrence policies.

\begin{tabular}{|c|c|c|c|c|c|}
\hline & $\begin{array}{l}\text { Manual } \\
\text { Premium }\end{array}$ & $\begin{array}{c}\text { Mean } \\
\text { Discount/ } \\
\text { Surcharge } \\
\text { Adjusted } \\
\text { Premium } \\
\end{array}$ & $\begin{array}{c}\text { Low } \\
\text { Premium }\end{array}$ & $\begin{array}{c}\text { Median } \\
\text { Discount// } \\
\text { Surcharge } \\
\text { Adjusted } \\
\text { Premium } \\
\end{array}$ & $\begin{array}{c}\text { High } \\
\text { Premium }\end{array}$ \\
\hline \multicolumn{6}{|c|}{$2000 \$ 1 / \$ 3$ Million Occurrence Policies } \\
\hline Ortho/ Spinal * & $\$ 43,687$ & $\$ 33,028$ & $\$ 21,844$ & $\$ 30,581$ & $\$ 56,794$ \\
\hline Neurology & $\$ 62,182$ & $\$ 46,481$ & $\$ 31,091$ & $\$ 43,527$ & $\$ 80,837$ \\
\hline Ob/Gyn** & $\$ 69,361$ & $\$ 53,172$ & $\$ 34,681$ & $\$ 55,489$ & $\$ 90,170$ \\
\hline Tier 1 Mean & $\$ 61,148$ & $\$ 50,134$ & $\mathrm{~N} / \mathrm{A}$ & & $\mathrm{N} / \mathrm{A}$ \\
\hline \multicolumn{6}{|c|}{2005 \$1/ \$3 Million Occurrence Policies } \\
\hline Ortho/ Spinal ${ }^{*}$ & $\$ 72,080$ & $\$ 60,028$ & $\$ 36,040$ & $\$ 57,664$ & $\$ 85,496$ \\
\hline Neurology & $\$ 90,710$ & $\$ 74,056$ & $\$ 45,355$ & $\$ 72.568$ & $\$ 108,852$ \\
\hline Ob/Gyn** & $\$ 97,243$ & $\$ 85,979$ & $\$ 48,622$ & $\$ 77,794$ & $\$ 145,865$ \\
\hline Tier 1 Mean & $\$ 86,678$ & $\$ 82,936$ & N/A & & N/A \\
\hline \multicolumn{6}{|c|}{2000 \$2/ \$6 Million Occurrence Policies } \\
\hline Ortho/ Spinal* & $\$ 61,442$ & N/A & $\mathrm{N} / \mathrm{A}$ & $\mathrm{N} / \mathrm{A}$ & $\mathrm{N} / \mathrm{A}$ \\
\hline Neurology & $\$ 87,451$ & $\$ 64,268$ & $\$ 43,726$ & $\$ 61,216$ & $\$ 96,196$ \\
\hline Ob/Gyn** & $\$ 97,550$ & $\$ 76,723$ & $\$ 48,775$ & $\$ 78,040$ & $\$ 117,060$ \\
\hline Tier 1 Mean & $\$ 85,998$ & $\$ 74,647$ & N/A & & $\mathrm{N} / \mathrm{A}$ \\
\hline \multicolumn{6}{|c|}{$2005 \$ 2 / \$ 6$ Million Occurrence Policies } \\
\hline Ortho/ Spinal ${ }^{*}$ & $\$ 89,559$ & $\$ 80,603$ & $\$ 71,647$ & $\$ 80,603$ & $\$ 89,559$ \\
\hline Neurology & $\$ 112,706$ & $\$ 112,706$ & $\$ 112,706$ & $\$ 112,706$ & $\$ 112,706$ \\
\hline Ob/Gyn** & $\$ 120,823$ & $\$ 122,962$ & $\$ 108,741$ & $\$ 120,823$ & $\$ 157,070$ \\
\hline Tier 1 Mean & $\$ 110,978$ & $\$ 116,429$ & N/A & & N/A \\
\hline
\end{tabular}

Source: Medical Professional Mutual Insurance Co.

Note: All data adjusted by Consumer Price Index and expressed in constant 2005 dollars.

*Ortho/Spinal: Orthopedics performing spinal surgery;

**OB/GYN includes OB/major surgery. 
Figure 18. Percentage distribution of physicians receiving various discounts and surcharges in top three practice specialties, for $\$ 1 / \$ 3$ million and $\$ 2 / \$ 6$ million occurrence policies, 2000-2005.

\begin{tabular}{|c|c|c|c|c|c|c|c|c|c|c|c|c|}
\hline & \multicolumn{4}{|c|}{ Ortho/Spinal Surgery* } & \multicolumn{4}{|c|}{ Neurology } & \multicolumn{4}{|c|}{ Obstetrics/Gynecology } \\
\hline & \multicolumn{2}{|c|}{$\begin{array}{c}\text { \$1/ } \$ 3 \text { Million } \\
\text { Occurrence }\end{array}$} & \multicolumn{2}{|c|}{$\begin{array}{c}\$ 2 / \$ 6 \\
\text { Million } \\
\text { Occurrence }\end{array}$} & \multicolumn{2}{|c|}{$\begin{array}{c}\text { \$1/ } \$ 3 \text { Million } \\
\text { Occurrence }\end{array}$} & \multicolumn{2}{|c|}{$\begin{array}{l}\text { \$2/\$6 Million } \\
\text { Occurrence }\end{array}$} & \multicolumn{2}{|c|}{$\begin{array}{c}\text { \$1/ } \$ 3 \text { Million } \\
\text { Occurrence }\end{array}$} & \multicolumn{2}{|c|}{$\begin{array}{c}\$ 2 / \$ 6 \\
\text { Million } \\
\text { Occurrence }\end{array}$} \\
\hline & 2000 & 2005 & 2000 & 2005 & 2000 & 2005 & 2000 & 2005 & 2000 & 2005 & 2000 & 2005 \\
\hline $\begin{array}{c}50 \% \\
\text { Discount }\end{array}$ & $8 \%$ & $6 \%$ & $0 \%$ & $0 \%$ & $18 \%$ & $7 \%$ & $22 \%$ & $0 \%$ & $11 \%$ & $2 \%$ & $0 \%$ & $0 \%$ \\
\hline $\begin{array}{c}40 \% \\
\text { Discount }\end{array}$ & $22 \%$ & $0 \%$ & 0 & $0 \%$ & $15 \%$ & $0 \%$ & $7 \%$ & $0 \%$ & $14 \%$ & $\%$ & $33 \%$ & $0 \%$ \\
\hline $\begin{array}{c}30 \% \\
\text { Discount }\end{array}$ & $24 \%$ & $28 \%$ & $0 \%$ & $0 \%$ & $23 \%$ & $30 \%$ & $36 \%$ & $0 \%$ & $19 \%$ & $27 \%$ & $17 \%$ & $0 \%$ \\
\hline $\begin{array}{c}20 \% \\
\text { Discount }\end{array}$ & $26 \%$ & $28 \%$ & $0 \%$ & $50 \%$ & $23 \%$ & $21 \%$ & $7 \%$ & $0 \%$ & $34 \%$ & $26 \%$ & $10 \%$ & $0 \%$ \\
\hline $\begin{array}{c}10 \% \\
\text { Discount }\end{array}$ & $6 \%$ & $17 \%$ & $0 \%$ & $0 \%$ & $10 \%$ & $30 \%$ & $14 \%$ & $0 \%$ & $10 \%$ & $21 \%$ & $27 \%$ & $6 \%$ \\
\hline $\begin{array}{l}\text { Manual } \\
\text { Rate }\end{array}$ & $8 \%$ & $11 \%$ & $100 \%$ & $50 \%$ & $5 \%$ & $5 \%$ & $7 \%$ & $100 \%$ & $6 \%$ & $3 \%$ & $7 \%$ & $82 \%$ \\
\hline $\begin{array}{c}10 \% \\
\text { Surcharge }\end{array}$ & $2 \%$ & $6 \%$ & $0 \%$ & $0 \%$ & $0 \%$ & $0 \%$ & $7 \%$ & $0 \%$ & $0 \%$ & $8 \%$ & $0 \%$ & $6 \%$ \\
\hline $\begin{array}{c}20 \% \\
\text { Surcharge }\end{array}$ & $0 \%$ & $6 \%$ & $0 \%$ & $0 \%$ & $5 \%$ & $7 \%$ & $0 \%$ & $0 \%$ & $4 \%$ & $7 \%$ & $7 \%$ & $0 \%$ \\
\hline $\begin{array}{c}30 \% \\
\text { Surcharge }\end{array}$ & $4 \%$ & $0 \%$ & $0 \%$ & $0 \%$ & $3 \%$ & $0 \%$ & $0 \%$ & $0 \%$ & $2 \%$ & $3 \%$ & $0 \%$ & $6 \%$ \\
\hline $\begin{array}{c}40 \% \\
\text { Surcharge }\end{array}$ & $0 \%$ & $0 \%$ & $0 \%$ & $0 \%$ & $0 \%$ & $0 \%$ & $0 \%$ & $0 \%$ & $0 \%$ & $1 \%$ & $0 \%$ & $0 \%$ \\
\hline $\begin{array}{c}50 \% \\
\text { Surcharge }\end{array}$ & $0 \%$ & $0 \%$ & $0 \%$ & $0 \%$ & $0 \%$ & $0 \%$ & $0 \%$ & $0 \%$ & $0 \%$ & $2 \%$ & $0 \%$ & $0 \%$ \\
\hline
\end{tabular}

Source: Medical Professional Mutual Insurance Co.

Note: Ortho/Spinal: Orthopedics performing spinal surgery. 
Figure 19. OB/GYN manual rates and mean, low, and high premiums adjusted for discounts and surcharges, for 2000 and 2005 for $\$ 1 / \$ 3$ million first year through mature claims-made and occurrence policies, 1990 manual rates.

\begin{tabular}{|c|c|c|c|c|c|c|c|}
\hline \multicolumn{8}{|c|}{2000} \\
\hline $\begin{array}{c}\text { Ob/Gyn } \\
\text { \$1/S3 } \\
\text { Million } \\
\text { Policies }\end{array}$ & Count & $\begin{array}{c}2000 \\
\text { Manual } \\
\text { Rate }\end{array}$ & $\begin{array}{c}\text { Mean } \\
\text { Discount/ } \\
\text { Surcharge } \\
\text { Adjusted } \\
\text { Premium }\end{array}$ & $\begin{array}{c}\text { Low } \\
\text { Premium }\end{array}$ & $\begin{array}{l}\text { Median } \\
\text { Discount/ } \\
\text { Surcharge } \\
\text { Adjusted } \\
\text { Premium }\end{array}$ & $\begin{array}{c}\text { High } \\
\text { Premium }\end{array}$ & $\begin{array}{c}1990 \\
\text { Manual } \\
\text { Rate }\end{array}$ \\
\hline $\begin{array}{c}\text { 1st Year } \\
\text { CM }\end{array}$ & 0 & $\$ 9,313$ & & & & & $\$ 6,100$ \\
\hline $\begin{array}{c}\text { 2nd Year } \\
\text { CM }\end{array}$ & 0 & $\$ 19,849$ & & & & & $\$ 16,763$ \\
\hline $\begin{array}{c}\text { 3rd Year } \\
\text { CM }\end{array}$ & 0 & $\$ 36,567$ & & & & & $\$ 31,242$ \\
\hline $\begin{array}{c}\text { 4th Year } \\
\text { CM }\end{array}$ & 0 & $\$ 60,031$ & & & & & $\$ 52,383$ \\
\hline $\begin{array}{c}\text { Mature } \\
\text { CM }\end{array}$ & 31 & $\$ 74,561$ & $\$ 63,016$ & $\$ 37,281$ & $\$ 59,649$ & $\$ 96,930$ & $\$ 68,359$ \\
\hline Occurrence & 242 & $\$ 69,361$ & 53,172 & $\$ 34,681$ & $\$ 555,489$ & $\$ 90,170$ & \$69,086 \\
\hline \multicolumn{8}{|c|}{2005} \\
\hline $\begin{array}{c}\text { Ob/Gyn } \\
\text { \$1/\$3 } \\
\text { Million } \\
\text { Policies }\end{array}$ & Count & $\begin{array}{c}2005 \\
\text { Manual } \\
\text { Rate }\end{array}$ & $\begin{array}{c}\text { Mean } \\
\text { Discount/ } \\
\text { Surcharge } \\
\text { Adjusted } \\
\text { Premium } \\
\end{array}$ & $\begin{array}{c}\text { Low } \\
\text { Premium }\end{array}$ & $\begin{array}{c}\text { Median } \\
\text { Discount/ } \\
\text { Surcharge } \\
\text { Adjusted } \\
\text { Premium } \\
\end{array}$ & $\begin{array}{c}\text { High } \\
\text { Premium }\end{array}$ & $\begin{array}{c}1990 \\
\text { Manual } \\
\text { Rate }\end{array}$ \\
\hline $\begin{array}{c}\text { 1st Year } \\
\text { CM }\end{array}$ & 21 & $\$ 31,503$ & 27,303 & 22,052 & $\$ 25,202$ & $\$ 47,255$ & $\$ 6,100$ \\
\hline $\begin{array}{c}\text { 2nd Year } \\
\text { CM }\end{array}$ & 15 & $\$ 52,502$ & $\$ 60,902$ & $\$ 36,751$ & $\$ 63,002$ & $\$ 78,753$ & $\$ 16,763$ \\
\hline $\begin{array}{c}\text { 3rd Year } \\
\text { CM }\end{array}$ & 4 & $\$ 78,754$ & $\$ 72,847$ & $\$ 55,128$ & $\$ 66,941$ & $\$ 102,380$ & $\$ 31,242$ \\
\hline $\begin{array}{c}\text { 4th Year } \\
\text { CM }\end{array}$ & 13 & $\$ 94,506$ & $\$ 87,963$ & $\$ 66,154$ & $\$ 85,055$ & $\mathbf{\$ 1 1 3 , 4 0 7}$ & $\$ 52,383$ \\
\hline $\begin{array}{c}\text { Mature } \\
\text { CM }\end{array}$ & 13 & $\$ 105,006$ & $\$ 102,583$ & $\$ 52,503$ & $\$ 105,006$ & $\$ 136,508$ & $\$ 68,359$ \\
\hline Occurrence & 182 & $\$ 97,243$ & 85,979 & $\$ 48,621$ & $\$ 77,794$ & $\$ 145,865$ & $\$ 69,086$ \\
\hline
\end{tabular}

Source: Medical Professional Mutual Insurance Co.

Note: All data adjusted by CPI and expressed in constant 2005 dollars.

CM: Claims made.

K. An Unrecognized Factor Leading to Selective Increases in Premiums

Premiums did not increase uniformly for high-risk physicians in the years following 1990; rather, they declined for nearly a third of physicians and increased substantially for most of the others. There is another factor not generally recognized that explains this phenomena: changes in medical underwriting. After 1990, PMG extended 
underwriting within practice specialties through premium discounts and surcharges based on individual risk factors. It reduced premiums for lower risk physicians and increased them for those with higher risks.

Physicians within Tier 1 paid identical premiums in 1990; by 2005 , however, their premiums varied three-fold. In 2005, nearly onethird of OB/GYNs paid less than 1990 rates while 28 percent paid $\$ 28,150$ or more than 1990 rates. Refining risk ratings contributed significantly to the increased premiums for high-risk OB/GYNs, while it lowered premiums for lower risk OB/GYNs. As a result, the cost of insurers lowering premiums for some OB/GYNs was a higher premium for high risk OB/GYNs.

If PMG changed all OB/GYNs the same amount in 2005, averaging high and low premiums and all discounts and surcharges, rates would have increased for this specialty by less than $\$ 16,900$ since 1990. ${ }^{144}$ By both differentiating risk and charging premiums according to risk, premiums in 2005 instead varied between $\$ 48,621$ (a decrease of $\$ 20,465$ from 1990) and $\$ 145,865$ (an increase of $\$ 76,780$ since 1990). When OB/GYNs seeking lower premiums compelled insurers to compete for business, PMG lowered premiums for low risk OB/GYNs. Those low risk OB/GYNs then stopped subsidizing highrisk OB/GYNs. The result? Lower premiums for a few OB/GYNs, somewhat higher premiums for most, and much higher premiums for a few. In short, one reason that premiums increased for some OB/GYNs, is that insurers sought to price individual policies based on assessed risk rather than to spread that risk across all OB/ GYNs as a group.

In 2005, 21 percent of OB/GYNs paid rate surcharges. Eight percent paid a 10 percent surcharge, 7 percent paid a 20 percent surcharge, 3 percent paid a 30 percent surcharge, and 3 percent paid either a 40 percent or 50 percent surcharge. Furthermore, 76 percent of OB/GYNs received discounts. Twenty-one percent of OB/GYNs received a 10 percent discount, 26 percent received a 20 percent discount, 27 percent received a 30 percent discount, and 2 percent received a 50 percent discount.

Insurers in other markets often employ individual risk rating. Health insurers that sell individual policies typically use risk rating, charging steep premiums to high-risk individuals or denying them coverage altogether. Most people, however, obtain health insurance through employers, which spreads the risk across all employees and makes insurance affordable for high-risk individuals. Enterprise

144. This number is obtained by taking the 2005 mean discount-andsurcharge-adjusted premium for $\$ 1 \mathrm{M} / \$ 3 \mathrm{M}$ occurrence policies $(\$ 85,970)$ and subtracting the 1990 manual rate $(\$ 69,970)$ for $\$ 1 \mathrm{M} / \$ 3 \mathrm{M}$ occurrence policies. See Figure 19 supra. 
liability is an equivalent mechanism to pool risk and subsidize highrisk individuals for malpractice insurance. It shifts legal and financial responsibility from individual physicians to organizations such as hospitals.

\section{Changes in Policies Purchased}

The analysis so far is of pure price increases and decreases for a constant product, namely insurance policies for a set dollar amount of coverage. Another reason for rising or decreasing expenditures is that people may purchase different products. When considering claims that premium costs are out of control, it is important to define what the product is that physicians are purchasing and whether the product has changed.

Car prices, for example, can increase because the manufacturer or dealers choose to charge more or because the kind of car people purchase changes over time. Consider cars throughout the last several decades: They have added features such as air-bag restraint systems, antilock brakes, catalytic converters to reduce harmful emissions, and computer chips to manage various functions. Manufacturers also redesigned engines to make cars more fuel efficient, changed the design and components to make them safer, and made numerous other changes in the material used and in the design.

In comparing cars of the past with those of today we need to consider the reasons for the price change: is it due to specific changes in the product, or has the price changed despite the product remaining the same? When purchasing professional liability insurance, the product is a defined dollar amount of liability protection for a certain period. Insurers have not significantly changed the configuration of their policies, and as a result, it is much easier to gauge pure price increase over time.

Furthermore, physicians may purchase a greater dollar level of coverage today than in the past, which increases the amount they pay, even if the price of the policy remains constant. They may purchase greater coverage because they risk greater liability, or because they are obliged to do so by state laws or hospitals as a condition for having practice privileges. They may also purchase higher dollar amounts of coverage on their own to obtain greater protection.

It is worth noting that the increased dollar amounts of liability protection do not cost proportionately more. This is because the probability of the physician being held liable does not increase based on the policy purchased. Further, physicians found liable for malpractice are not usually liable for the maximum amount of their policy.

Since 1975 the Massachusetts Board of Registration in Medicine required physicians to purchase up to $\$ 100,000$ coverage per claim, 
capped at a $\$ 300,000$ yearly loss. ${ }^{145}$ Nevertheless, the most commonly purchased policy is $\$ 1 / \$ 3$ million. Between 1990 and 2005, many physicians increased coverage limits and paid more for the new policies. Figure 20 displays the distribution of all policies by type and dollar coverage from 1990 to 2005. Physicians purchasing $\$ 1 / \$ 3$ million policies decreased from 71.3 percent to 67.4 percent; those purchasing $\$ 2 / \$ 6$ million policies jumped from 8.4 percent to 30.3 percent.

Physicians also switched to less expensive policy types. Those purchasing mature claims-made policies - the most expensive category-fell from 25.4 percent to 10.7 percent. Physicians purchasing occurrence policies - the second most expensive typeincreased from 72.6 to 83.2 percent. Physicians with first-year through fourth-year claims-made policies increased from 2 to 6 percent. Purchasing less expensive types of policies, however, is different. Since such changes are based on the duration of time covered, physicians would need to purchase other policies over that time.

145. 243 Mass. Code Regs. 2.07 (16) (1987). Many states do not require physicians to purchase malpractice liability insurance and many states that do require that they purchase a low level of coverage. See Hyman et al., supra note 11 , at 55 . 
Figure 20. Estimate, distribution of polices sold by dollar amount of coverage and by major types of policy, 1990-2005.

\begin{tabular}{|c|c|c|c|c|c|c|c|}
\hline YEAR & $\begin{array}{l}\text { TYPE OF } \\
\text { POLICY }\end{array}$ & $\begin{array}{l}\$ 1 M / \\
\$ 3 M\end{array}$ & $\begin{array}{l}\$ 2 M / \\
\$ 6 M\end{array}$ & 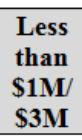 & 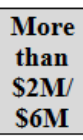 & Undefined & $\begin{array}{l}\text { Total \% } \\
\text { of Each } \\
\text { Type of } \\
\text { Policy }\end{array}$ \\
\hline \multirow{4}{*}{1990} & $\begin{array}{l}\text { Less than Mature } \\
\text { Claims Made }\end{array}$ & $1.2 \%$ & $0.4 \%$ & $0.1 \%$ & $0.0 \%$ & $0.2 \%$ & $2.0 \%$ \\
\hline & $\begin{array}{l}\text { Mature Claims } \\
\text { Made }\end{array}$ & $17.0 \%$ & $2.6 \%$ & $1.5 \%$ & $0.0 \%$ & $4.3 \%$ & $25.4 \%$ \\
\hline & Occurrence & $53.1 \%$ & $5.4 \%$ & $6.4 \%$ & $0.0 \%$ & $7.7 \%$ & $72.6 \%$ \\
\hline & $\begin{array}{c}\text { Total } \% \text { of } \$ \\
\text { Coverage } \\
\text { Purchased }\end{array}$ & $71.3 \%$ & $8.4 \%$ & $8.1 \%$ & $0.0 \%$ & $12.3 \%$ & $100.0 \%$ \\
\hline \multirow{4}{*}{1995} & $\begin{array}{c}\text { Less than Mature } \\
\text { Claims Made }\end{array}$ & $0.9 \%$ & $0.3 \%$ & $0.0 \%$ & $0.0 \%$ & $0.0 \%$ & $1.2 \%$ \\
\hline & $\begin{array}{l}\text { Mature Claims } \\
\text { Made }\end{array}$ & $16.4 \%$ & $2.3 \%$ & $1.1 \%$ & $0.0 \%$ & $0.0 \%$ & $19.8 \%$ \\
\hline & Occurrence & $66.6 \%$ & $8.9 \%$ & $3.5 \%$ & $0.0 \%$ & $0.0 \%$ & $79.0 \%$ \\
\hline & $\begin{array}{c}\text { Total \% of } \$ \\
\text { Coverage } \\
\text { Purchased }\end{array}$ & $83.9 \%$ & $11.5 \%$ & $4.6 \%$ & $0.0 \%$ & $0.0 \%$ & $100.0 \%$ \\
\hline \multirow{4}{*}{2000} & $\begin{array}{l}\text { Less than Mature } \\
\text { Claims Made }\end{array}$ & $0.3 \%$ & $0.2 \%$ & $0.0 \%$ & $0.0 \%$ & 0.0 & $0.6 \%$ \\
\hline & $\begin{array}{l}\text { Mature Claims } \\
\text { Made }\end{array}$ & $10.9 \%$ & $2.3 \%$ & $0.2 \%$ & $0.1 \%$ & $0.0 \%$ & $13.5 \%$ \\
\hline & Occurrence & $61.0 \%$ & $22.9 \%$ & $0.6 \%$ & $1.3 \%$ & $0.1 \%$ & $85.9 \%$ \\
\hline & $\begin{array}{c}\text { Total \% of \$ } \\
\text { Coverage } \\
\text { Purchased }\end{array}$ & $72.2 \%$ & $25.4 \%$ & $0.8 \%$ & $1.4 \%$ & $0.1 \%$ & $100.0 \%$ \\
\hline \multirow{4}{*}{2005} & $\begin{array}{c}\text { Less than Mature } \\
\text { Claims Made }\end{array}$ & $4.8 \%$ & $1.2 \%$ & $0.0 \%$ & $0.0 \%$ & $0.0 \%$ & $6.0 \%$ \\
\hline & $\begin{array}{l}\text { Mature Claims } \\
\text { Made }\end{array}$ & $8.0 \%$ & $2.6 \%$ & $0.1 \%$ & $0.1 \%$ & $0.0 \%$ & $10.7 \%$ \\
\hline & Occurrence & $54.6 \%$ & $26.6 \%$ & $0.6 \%$ & $1.5 \%$ & $0.0 \%$ & $83.2 \%$ \\
\hline & $\begin{array}{c}\text { Total \% of } \$ \\
\text { Coverage } \\
\text { Purchased }\end{array}$ & $67.4 \%$ & $30.3 \%$ & $0.7 \%$ & $1.6 \%$ & $0.0 \%$ & $100.0 \%$ \\
\hline
\end{tabular}

How should we interpret changes in the kind of insurance policies that physicians purchase, particularly increases in the dollar amount of liability coverage? When physicians are compelled to purchase greater amounts of liability protection clearly that is a cost of practice they cannot avoid. In this case, it makes sense to consider such cost increases as an increased cost of practice even if the price of insurance has not increased. We can summarize this by saying that physicians needed to purchase greater levels of liability coverage to practice medicine. 
But what about physicians who purchase greater amounts of liability protection even though they are not required to by state law, hospital policy, or other rules? If physicians need more protection because awards are higher and they cannot reasonably practice with the same amount of coverage as they did previously, it seems reasonable to take account of that also. If all or most physicians purchased greater dollar levels of liability protection, then it seems prudent to assume these physicians generally needed to purchase more insurance. But if over time only a small percentage of physicians purchase greater coverage, then it would be unreasonable to assume physicians need that extra insurance. Instead, their purchases should be considered as a reflection of their preferences, risk aversion, or other factors.

\section{Comparison of ProMutual Group Premiums to Premiums of Other Insurers}

As noted, the PMG dominates the Massachusetts Professional Liability Insurance Market outside of Harvard's CRICO. Its large size suggests that the bulk of its policies reflect what most physicians in the state pay. Still, if PMG's physicians had lower risk than other insurers, then its premiums might understate the prices paid by those other physicians. The evidence, however, suggests that this is unlikely. Indeed, there are strong grounds to assert that PMG's premiums are higher than other insurers, especially for high-risk physicians.

First, PMG cannot effectively preclude high-risk physicians. Massachusetts regulations prohibit insurers from refusing any applicant. It is true that Massachusetts insurers can cede risk and insurance premiums to a state mandated reinsurance program for any policy holder they do not wish to cover. The program would then divide the costs among insurers based on respective market shares. But ProMutual Group possesses between 88 and 91 percent of the market and would bear that portion of the cost regardless. Therefore, even if PMG cedes risk to the state pool, it would save very little money by doing so. The opposite is true of insurers who have a small market share. Since its start in 1995, the reinsurance plan included between zero and 10 percent of insurance sales.

Second, evidence suggests that PMG charges higher premiums than its competitors for physicians such as OB/GYNs. Two regulated insurers-Medical Protective and Connecticut Medical Insurance Company - appear to have developed niche markets by selling insurance to specialties that they believe are overcharged. In 2005, Medical Protective set lower rates than PMG: 14 percent, or $\$ 5,850$, less for orthopedists and 11 percent, or $\$ 11,602$, less for OB/GYNs. Still, the price that physicians actually paid is not publicly known because insurers do not disclose details about discounts and 
surcharges. Indeed, these insurers may sell insurance selectively to physicians with lower than normal risk for their practice specialty.

It also appears that some high-risk physicians have declined insurance from the ProMutual Group to purchase it at a lower price from other insurers. PMG analyzed Board of Registration of Medicine data in 1997 and found that OB/GYNs comprised 4 percent of Massachusetts physicians, the same amount as its policyholders. Between 2000 and 2005, however, the number of OB/GYNs that purchased insurance from PMG declined from 242 to 182 for $\$ 1 / \$ 3$ million coverage and from 55 to 20 for $\$ 2 / \$ 6$ million coverage.

Similarly, PMG's physicians in the top rate group for $\$ 1 / \$ 3$ million occurrence policies decreased from 4.4 percent in 1995 to 3.2 percent in 2005. Tier 1 represented 8 percent of PMG's physicians in 1990 but only 4 percent in 2005. The percentage of PMG's business that included high-risk physicians also decreased as other insurers sought a niche market for such physicians by offering them lower premiums. This data suggests that some physicians switched from ProMutual Group to its competitors to reduce their premiums.

Physicians in PMG's highest rate group are also likely to pay at least as much as similar physicians insured by risk-retention groups or offshore companies. Physicians choose such unregulated insurance to pay lower premiums. Otherwise, they would be incurring greater risk by purchasing insurance with lower financial reserves and less state regulatory protection without receiving any financial advantage.

CRICO also probably charges lower premiums to its physicians than is available on the open market. If it does not, then Harvard receives no financial benefit from creating this self-insurance pool, but it incurs significant administrative burden and financial risk.

\section{N. What Causes Premiums to Rise or Fall?}

Many physicians think that rises in liability insurance premiums are due to increases in either the number of malpractice lawsuits or the number and size of court awards and out of court settlements. That is not an unreasonable inference, but it misses other causes. Over the long term, premiums must reflect the costs of malpractice liability that insurance companies pay. However, in the short term, changes in premiums are more closely related to market competition, the interest rate earned by insurers on their investments, and insurers' predictions about risk. Indeed, careful economic analysis reveals that there are cycles of rises and falls in premiums for all categories of insurance, which insurance analysts call underwriting cycles. ${ }^{146}$

Underwriting cycles are partly due to the long delay between when physicians purchase policies and when insurers incur loss. This

146. Baker, supra note 59, at 396. 
increases uncertainty and complicates accurate pricing of insurance risk. Market competition induces insurers to lower premiums to increase their market share until they revise upward predictions of future liabilities and reserve needs. Insurers then increase premiums sharply to make up for liabilities incurred several years before based on more optimistic estimates.

Changes in the investment climate also contribute to underwriting cycles. As interest rates rise, so does insurer income from reserves. When interest rates decline, insurer investment income falls. ${ }^{147}$ When insurer investment income declines, insurers typically raise premiums. And when insurer investment income increases, insurers typically lower premiums to increase their book of business. The result: underwriting market cycles. In what analysts refer to as hard markets, insurers carefully select risks, increase reserves, and raise premiums. During what analysts refer to as soft markets, insurers assume more risk, decrease reserves, and lower premiums. For instance, studies have shown that malpractice premiums rose in Texas in the 1980s and early 2000 because insurers changed long-term loss predictions and the investment climate soured, not because claims or awards increased in size or frequency. ${ }^{148}$

\section{Why the CRisis Persists}

\section{A. Physicians Mistakenly Perceive a Crisis}

Physicians and casual observers often conclude that there is a medical malpractice premium crisis because they rely on unreliable data or misinterpret accurate data. The most frequently reported data on malpractice premiums comes from the Medical Liability Monitor Reporter which reports average changes in premiums without distinguishing between the prices of premiums in different policies due to the dollar amount of coverage purchased, which of seven categories of policies are purchased, or the time period for which the physician is covered.

Most observers focus on the highest risk specialties. They believe the premiums for obstetricians and one or two other high-risk specialties represent what all other physicians pay. They do not understand that these high-risk practice premiums are atypical. Furthermore, many physicians and observers look at the premium rates published in the insurance manual, but in fact, insurers typically discount those rates for most physicians. Physicians also often fail to adjust for inflation, and therefore they exaggerate any premium

147. Kurt Karl et al., Capital Markets and Insurance Cycles, 4 J. RISK FIN. 40, 40-46 (2003).

148. Black, supra note 88, at 253. 
increases that do exist. They forget to incorporate the periods of time during which premiums remained about the same or decreased. Thus, to many physicians, it appears that their premiums increase steadily when in fact there were cycles of rises and falls.

Furthermore, press reports often dramatize premium increases by reporting percentage increases rather than changes in the dollar amount that a physician pays. It sounds more dramatic to report that a physician's premium increased 10 percent or 20 percent than to report that the premiums increased by $\$ 2,000$ or $\$ 4,000$, often just a small fraction of the total premium amount.

The psychology of malpractice also prompts physicians to perceive a crisis. Being sued is traumatic. Even when courts decide they are not liable, sparing them financial loss, physicians incur high emotional costs. The fear of being sued again imposes a psychological toll. ${ }^{149}$ The risk of being held liable for negligence challenges the physician's selfimage and sense of professional competence, and that causes cognitive dissonance.

It should come as no surprise that many physicians perceive the risk of liability as a major burden, even when their own premiums are a small part of their practice's expense. Fear of malpractice may even skew physicians' perception of how much they pay for liability insurance. When physicians are financially squeezed they might perceive malpractice premiums to be the culprit. In fact, when a physician's income does not grow, fails to keep up with inflation, or declines altogether, the problem is not usually due to malpractice premiums; rather, the problem is more typically due to health insurers that clamp down on the size of physician fees and deny payment for services that they deem unnecessary. Malpractice premiums can be a convenient scapegoat for frustrated physicians. ${ }^{150}$

149. See, e.g., Sara C. Charles, Jeffrey R. Wilbert, \& J. Franke, Sued and Nonsued Physicians' Self-Reported Reactions to Malpractice Litigation, 142 Am. J. PsyChIATRY 437, 437 (1985) (discussing whether reactions reporting are unique to physicians being sued); see Sara C. Charles, Coping With a Medical Malpractice Suit, 174 W. J. MED. 55, 55 (2001).

150. The risk of liability also helps physicians justify their entrepreneurial practices that boost their income with little or no benefit to patients. Physicians often challenge insurers denial of payment by arguing that they need to perform those tests, exams, and services in order to protect themselves from malpractice liability. In fact, physicians typically receive income from performing those tests that have marginal or no value, while the risk of liability for not preforming them is small and remote. 


\section{B. Key Actors Have an Interest in Maintaining the Perception of a Crisis}

A real medical malpractice crisis serves no one's interest, yet the perception of a crisis advances the agenda of certain actors. Many of these actors promote the impression that a premium crisis exists or do nothing to correct that misperception. Let us review how the AMA, the tort reform lobby, politicians, the media, and health law and policy researchers benefit from the perception of a crisis.

Although the AMA is the oldest organization representing physicians in the United States, its authority and membership has declined from its peak in the 1950s when it included about 60 percent of all U.S. physicians. Today less than one-third of practicing physicians are members, and numerous other physician organizations have grown to represent the divergent interests of various practice specialties. ${ }^{151}$ This presents a problem for the AMA, which needs to maintain membership support and revenue to survive.

As the AMA searches for ways to convince physicians to become or remain members, it has focused on the legal reform of medical liability. Medical malpractice is a consensus issue. The AMA's call to protect physicians from liability unites physicians more than any of its other proposals.

If physicians ceased to perceive medical malpractice as a pressing problem, that would undercut the value of one of the AMA's most visible campaigns. The motivation for physicians to join the organization would be reduced. It is therefore in the AMA's interest to maintain the perception of a medical malpractice crisis. That helps explain why the AMA cries crisis when malpractice premiums rise but does not publicize the declines in premiums. It also helps explain why the AMA opposed the Clinton administration's enterprise liability proposal, which would have made hospitals liable for any negligence of hospital-based physicians. The proposal would have removed physician liability, ending the AMA's need to lobby for reform of medical liability law.

Rallying under the banner of "tort reform," a segment of American businesses seek to reduce the legal responsibility of corporations for harms caused by their economic activities. The organizations funded to advance this agenda want to restrict the ability of injured individuals to file lawsuits, restrict juries from awarding punitive damages, and cap the amount of compensation

151. See generally Marc A. Rodwin, Medicine, Money \& Morals: Physicians' CONFliCts OF InTEREST (1993) (discussing the AMAs growth and policies); MARC A. RODWIn, CONFLiCTS OF INTEREST AND the Future of Medicine: The United States, France, and Japan (2011). 
that juries can require firms to pay. These organizations also try to mobilize public opinion through the media, lobby legislators, and bring lawsuits to change liability rules.

These organizations, however, face a significant obstacle. A large segment of the public is unsympathetic to the interests of corporations and empathizes with individuals who are harmed by corporate action. These organizations therefore try to bolster popular support for their agenda by building coalitions with physicians seeking to change medical liability rules. They know that the public is more sympathetic to doctors than to corporations, and they believe that they can advance their aims by framing their agenda as reform of liability law in general rather than only for corporations. The tort reform lobby benefits when the public believes there is a medical malpractice premium crisis because crisis - however fabricated -is more likely to result in broader changes to tort law.

Politicians benefit from the perception of a malpractice crisis because it creates an easy way for them to garner electoral support with little political risk. Candidates for office can please most physicians by giving a speech supporting the reform of medical liability law whereas taking a stand on physician payment, health insurance, or other health policy issues are likely to divide physicians and lose votes. In addition, changes in medical liability law would not require tax increases or cuts in government programs, making it an even more attractive political stance. National candidates cannot be blamed for not producing legislative relief after elections because ultimately it is the states, not the federal government, that have jurisdiction over medical malpractice law.

George Bush backed medical malpractice reform in his presidential bids in 2000 and 2004..$^{152}$ Barack Obama also spoke in favor of reform, but used a more nuanced approach. Rather than support caps on awards, he promoted the use of projects in interested states to demonstrate the feasibility of alternatives to the litigation to resolve medical malpractice claims. ${ }^{153}$ And in response, when Congress drafted the Affordable Care Act, it included small federal grants to

152. U.S. President George W. Bush, Remarks Following a Discussion on Medical Liability Reform in Collinsville, Illinois, 10 (Jan 5, 2005), available http://www.gpo.gov/fdsys/browse/collection.action?collectionCode=CP D. See also Peter Baker, Bush Campaigns to Curb Lawsuits; President Says "Junk" Litigation Is Driving Small-Town Doctors Out of Business, WASH. POST, Jan. 6, 2005, http://www.washingtonpost.com/wpdyn/articles/A50603-2005Jan5.html.

153. U.S. President Barack H. Obama, Address Before a Joint Session of the Congress on Health Care Reform, 7 (Sept. 9, 2009), available at http://www.gpo.gov/fdsys/browse/collection.action?collectionCode=CP D. 
support and evaluate demonstration projects in states that were interested in such experiments. ${ }^{154}$

Many journalists meanwhile like to write stories on the malpractice premium crisis because the topic appeals to general readerships. Editors are more likely to publish reports of a crisis than reports showing little or no change in premiums or analysis that is complex and inconclusive. Dry information and complex economic and social analysis do not make catchy headlines, hook readers, or sell papers. But reports of a crisis often do.

It is also an easy story to write. Simply report misleading numbers on rising premiums and sprinkle the text with quotes from the many physicians who complain about their rates or threaten to leave practice as a result of high premiums. Armed with a quotation from a physician stating how premiums affected his practice, reporters rarely feel they need to check how those premiums affect the physician's overall practice costs or income. Nor do many of these journalists ask whether the physicians would have retired early even if premiums had not increased, or whether the early retirement was due to physicians having earned enough money from their practice to build a sizable nest egg.

Good scholars should not skew their research results. Yet all policy scholars have a common bias - they believe that what they study is important. It is to be expected then that policy scholars who write on medical malpractice portray medical malpractice as a pressing problem or a crisis. Why else should anyone fund their research or read their studies? Malpractice researchers often differ in their assessment of the effect of current policies and the policies they recommend, but generally maintain that there is a crisis. Because it benefits those who write about medical malpractice for the policymakers and the public to believe that there is a malpractice crisis, we should not expect malpractice researchers to proclaim that there is not much of a problem. There is just too much incentive to claim otherwise.

154. See, e.g., Michelle M. Mello et al., Implementing Hospital-based Communication-and-resolution Programs: Lessons Learned in New York City, 33 Health AfF. 30, 30 (2014) (providing the results of one demonstration project with five New York City hospitals). 